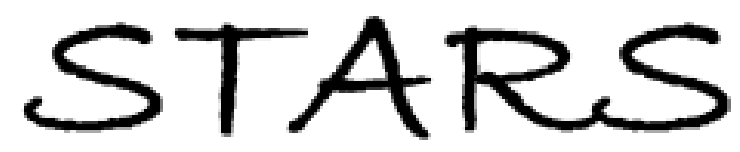

University of Central Florida

STARS

\title{
The Effects Of Exposure To Feminist Ideology On Women's Body Image
}

Rachel Diane Peterson

University of Central Florida

Part of the Psychology Commons

Find similar works at: https://stars.library.ucf.edu/etd

University of Central Florida Libraries http://library.ucf.edu

This Masters Thesis (Open Access) is brought to you for free and open access by STARS. It has been accepted for inclusion in Electronic Theses and Dissertations, 2004-2019 by an authorized administrator of STARS. For more information, please contact STARS@ucf.edu.

\section{STARS Citation}

Peterson, Rachel Diane, "The Effects Of Exposure To Feminist Ideology On Women's Body Image" (2005). Electronic Theses and Dissertations, 2004-2019. 372.

https://stars.library.ucf.edu/etd/372

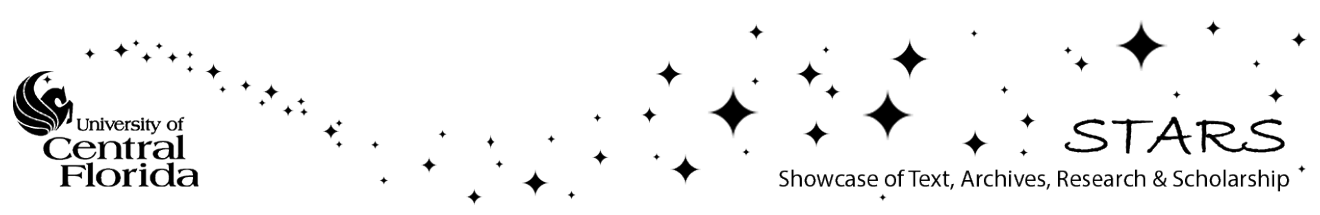


THE EFFECTS OF EXPOSURE TO FEMINIST

\title{
IDEOLOGY ON WOMEN'S BODY IMAGE
}

\author{
by \\ RACHEL D. PETERSON \\ B.A. Gustavus Adolphus College, 2001
}
A thesis submitted in partial fulfillment of the requirements for the degree of Master of Science in the Department of Psychology in the College of Arts and Sciences at the University of Central Florida Orlando, FL

Spring Term

2005 
C2005 Rachel D. Peterson 


\begin{abstract}
Body image disturbance has become an increasing problem among women (Cash \& Henry, 1995). Thus researchers have begun to focus on methods of prevention and intervention. Programs utilizing psychoeducation and Festinger's cognitive dissonance theory, for example, have been found to reduce body image dissatisfaction and related symptomatology. The information provided and potential impact are limited, however, because the interventions do not offer women an adaptive method of interpreting the many appearance-related messages they experience. This study sought to determine if exposure to feminist theory of body image may act as a buffer - a filter through which cultural messages about thinness and beauty are challenged. This feminist schema may provide an alternative interpretation of cultural messages, thereby increasing body image satisfaction. Participants were exposed to one of three interventions (feminist, psychoeducational, control). Exposure to the feminist condition resulted in increased physical appearance satisfaction and likelihood to self-identify as a feminist when compared with the control group. While findings were not extensive, they are nonetheless promising due to the brevity of the intervention.
\end{abstract}




\section{ACKNOWLEDGMENTS}

I want to start by thanking Dr. Stacey Tantleff Dunn for her countless hours of assistance throughout this process, particularly the numerous drafts edits. You have challenged me never to accept "good enough" and always work towards excellence. I appreciate your support and honest feedback. Thank you as well to my committee members, Dr. Michael E. Dunn and Dr. Janan Al-Awar Smither. Your constructive suggestions and ideas were essential to the creation of this project.

To my UCF classmates and fellow L.E.A.H. members, your willingness to assist me, both academically and personally, helped to make this project happen. Thank you to my research assistant, J. Michelle Daley, for her organization, enthusiasm, and hard work.

Thank you to my friends and family, particularly my mother, for never doubting me and supporting my dreams from across the country. Your calls, cards, and visits have helped me more than you know. 


\section{TABLE OF CONTENTS}

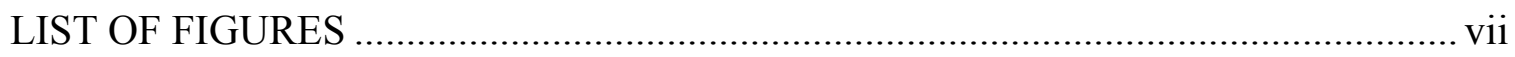

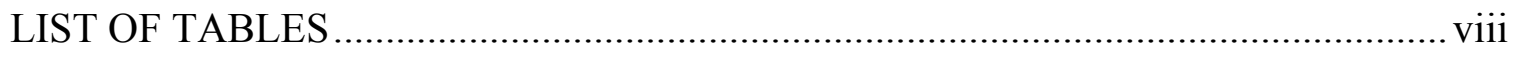

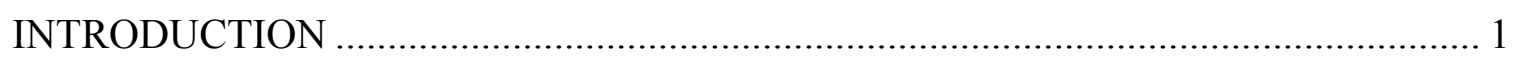

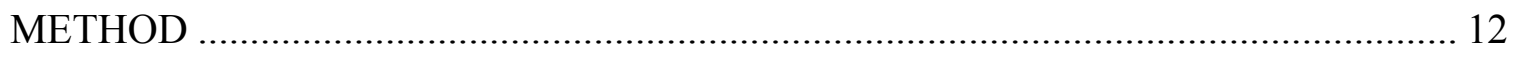

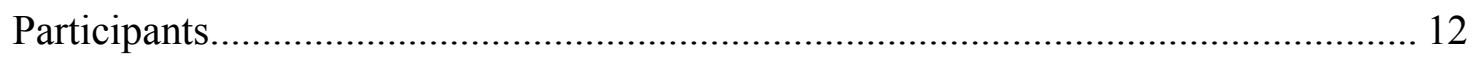

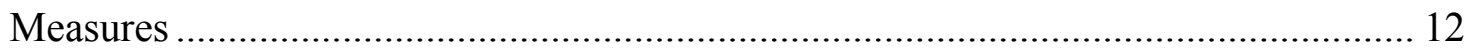

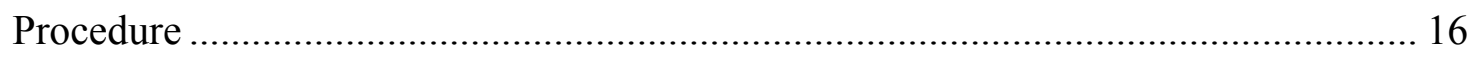

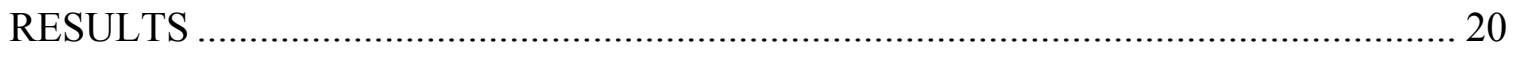

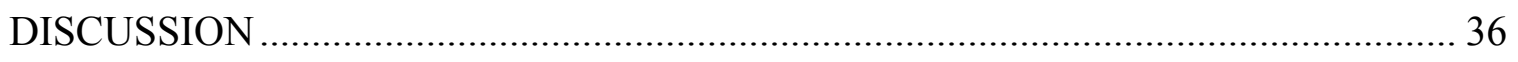

APPENDIX A: FEMINIST IDENTITY COMPOSITE ................................................ 43

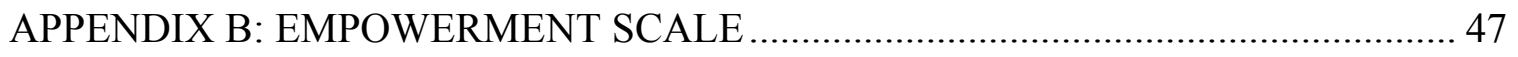

APPENDIX C: BEM SEX ROLE INVENTORY ……………................................... 51

APPENDIX D: SOCIOCULTURAL ATTITUDES TOWARD APPEARANCE

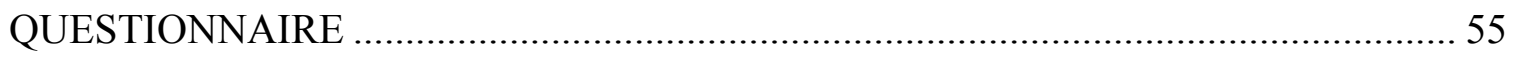

APPENDIX E: MULTIDIMENSIONAL BODY SELF-RELATIONS

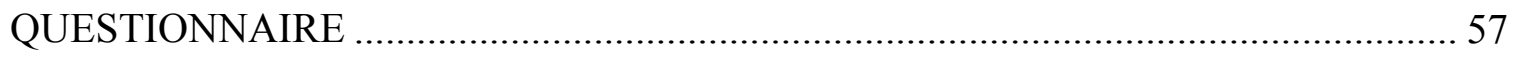

APPENDIX F: PHYSICAL APPEARANCE STATE AND TRAIT ANXIETY SCALE

APPENDIX G: APPEARANCE SCHEMA INVENTORY ............................................. 61

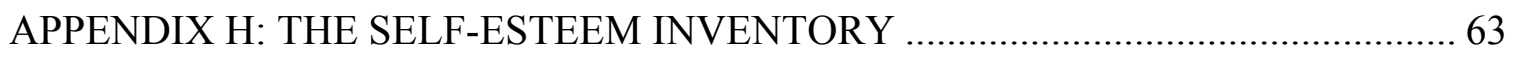

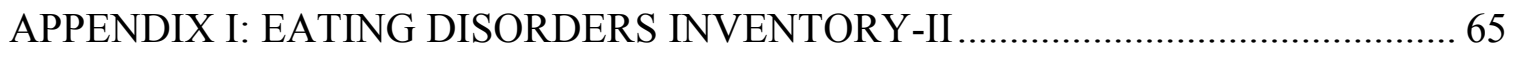

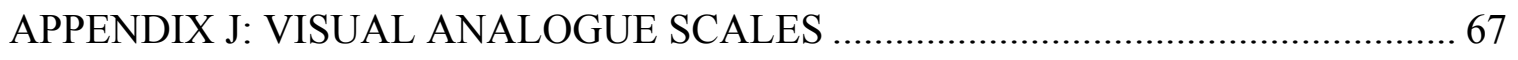


APPENDIX K: CONTOUR DRAWING RATING SCALE

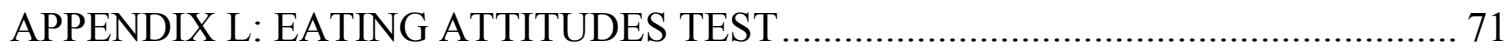

APPENDIX M: FEMINIST THEORY INTERVENTION TRANSCRIPT ………........ 73

APPENDIX N: FEMINIST THEORY INTERVENTION IMAGE EXAMPLE............... 81

APPENDIX O: PSYCHOEDUCATIONAL INTERVENTION TRANSCRIPT ............. 83

APPENDIX P: PSYCHOEDUCATIONAL INTERVENTION IMAGE EXAMPLE .... 91

APPENDIX Q: IRB HUMAN SUBJECTS APPROVAL LETTER ……………………... 93

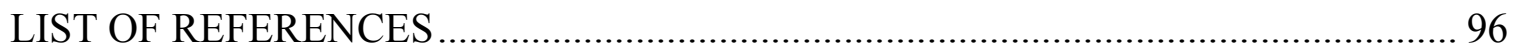




\section{LIST OF FIGURES}

Figure 1: Means and confidence intervals for feminist self-rating scores by condition.. 31

Figure 2: Mean and confidence intervals for physical appearance satisfaction scores by condition.

Figure 3: Mean and confidence intervals for body image vulnerability scores by condition. 


\section{LIST OF TABLES}

Table 1: Participants' demographic information at Time 1 .......................................... 22

Table 2: Time by condition repeated measures ANOVAS for the Visual Analogue Scale

Table 3: Time by condition repeated measures ANOVAS for measures of eating and

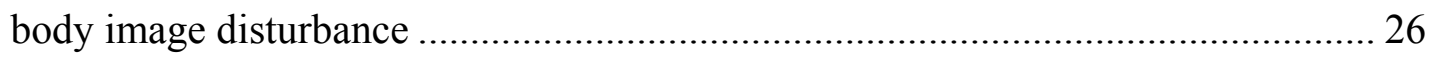

Table 4: Time by condition repeated measures ANOVAS for measures of body image

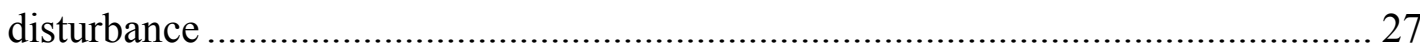

Table 5: Time by condition repeated measures ANOVAS for measures of body image

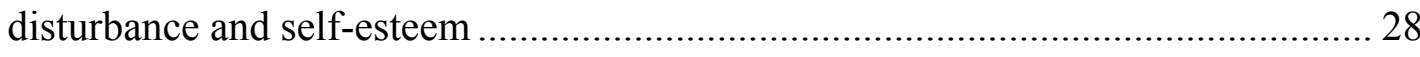

Table 6: Time by condition repeated measures ANOVAS for measures of feminism..... 29

Table 7: Time by condition repeated measures ANOVAS for the empowerment scale .. 30

Table 8: Reported effect sizes .............................................................................. 32

Table 9: Confidence intervals for reported effect sizes ................................................ 32

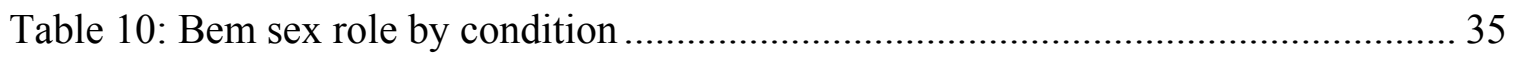




\section{INTRODUCTION}

Currently, weight concerns and food restriction are so common for women that they have become the societal norm (Rodin, Silberstein, \& Streigel-Moore, 1984). A national survey concluded that nearly $50 \%$ of women ages 18 to 70 evaluated their appearance negatively and were concerned about being or becoming overweight (Cash \& Henry, 1995). Characteristics of negative body image such as body dissatisfaction, drive for thinness, and low self-esteem are strongly correlated with and predictors of eating disorder symptomatology (Fulkerson, Perry, \& Cudeck, 1993; Stice, 1994). In addition to having poor body image, those suffering with eating disorders have low recovery rates, serious health problems, and the highest mortality rate of any mental illness (American Psychiatric Association, 2000; Fallon, Katzman, \& Wooley, 1994). Due to the alarming increase in prevalence of eating disorders and their grave consequences, research efforts to focus on interventions for and the prevention of body image and eating disturbance are needed greatly (Fallon, Katzman, \& Wooley, 1994; Stormer, 1999).

Many body image and eating disorder prevention and intervention methods have been researched (e.g., Baranowski \& Hetherington, 2001; Dahlgren Daigneault, 2000; Glidden \& Tracey, 1989; Irving \& Berel, 2001; Killen et al., 1993; Springer, Winzelberg, Perkins, \& Barr Taylor, 1999; Stice, Chase, Stormer, \& Appel, 2001; Stice, Mazotti, Weibel, \& Agras, 2000; Stice \& Ragan, 2002; Stice, Trost, \& Chase, 2003; Stormer, 1999; Tilgner, Wertheim, \& Paxton, 2004; Withers \& Wertheim, 2004; Zabinski et al., 2001). A recently published meta-analysis of 51 eating disorder prevention programs found small average effects sizes, Cohen's $d=.19, .13$, and .12 , at termination for healthy 
changes in thin-ideal internalization, body dissatisfaction, and eating pathology, respectively (Stice \& Shaw, 2004).

Several studies have focused on psychoeducational techniques that involve informing participants of the sociocultural influences on body image (Springer et al., 1999; Stice \& Ragan, 2002; Stormer, 1999). A recent intervention (Stormer, 1999) presented information to participants in video format and concentrated on topics such as the history of beauty ideals for women and the lengths to which women have gone to attain them (i.e. foot binding and corsets). The video also emphasized that today's media images represent an ideal that is not attainable even by the photographed model, since techniques such as airbrushing, plastic surgery, and computer altering are utilized regularly. The control group watched a video on nutrition and exercise. The experimental condition resulted in significantly lowered acceptance of sociocultural norms of beauty for women and men, increased the body size females felt would be most attractive to men, and increased the smallest acceptable dating figure for men as compared to the control group. There also was a nonsignificant trend towards reducing body image anxiety.

Another intervention study tested internally based (i.e., focused on potentially destructive cognitions regarding one's appearance that result from beauty norms and how to challenge the thoughts) versus externally based (i.e., educating women to question media imposed beauty norms and showing them ways to work towards societal changes) intervention programs (Irving \& Berel, 2001). The two intervention groups were compared to a video-only intervention and a no-intervention control group. Three groups watched "Slim Hopes" (Kilbourn, 1995), a video about society's preoccupation with 
thinness and harmful media messages. Following the video, the internal and external groups participated in structured discussions regarding sociocultural influences on body image specific to their intervention. This intervention resulted in increased media skepticism; however, there were no group differences in the post-test only measures of body image and media internalization (Irving \& Berel, 2001).

Researchers have taken interventions one-step further by implementing college courses on the topic of body image (Springer et al., 1999; Stice \& Ragan, 2002). Springer and colleagues (1999) found that class lectures on topics such as body image, culture, and obesity significantly reduced body image dissatisfaction and eating disorder symptomatology. Stice and Ragan (2002) found that an intensive psychoeducational college course focused on body image reduced body part dissatisfaction, dieting, and eating disorder symptomatology.

Although these intensive college classes significantly reduced body image disturbance, it is unlikely that most psychoeducational interventions will result in behavioral changes (Moskowitz, 1989). Therefore, Stice and colleagues (2000, 2001, 2003) tested interventions based on Festinger's cognitive dissonance theory. To investigate this theory, college women were recruited on the premise of helping researchers to evaluate body image programs for women. This required the women to take a stance against the thin ideal and in turn create cognitive dissonance. Both the pilot (Stice et al., 2000) and follow-up study (Stice et al., 2001) significantly decreased internalization of the thin ideal, body dissatisfaction, negative affect, and bulimic symptomatology. A further comparison (Stice et. al, 2003) led to similar results, with the exception of body dissatisfaction, which did not change significantly. These studies also 
supported the hypothesis that intervention methods may be most beneficial to those with already high levels of symptomatology (Stice et al., 2000). Stice and colleagues (2001) emphasized the need for additional experimental studies to identify effective intervention methods.

Glidden and Tracey (1989) asked female participants to watch a video of a mock therapy session to assess women's preferences for different types of interventions. In one version, the therapist focused on the sociocultural theory of body image disturbance (e.g., unattainable expectations) and the other focused on personal responsibility (e.g., exercise, nutrition). The researchers hypothesized that nontraditional women would be more receptive to the sociocultural intervention and traditional women would prefer the personally based intervention. Contrary to their hypotheses, and only among women with high weight concern, the traditional women preferred the sociocultural approach, whereas the nontraditional women favored the personal responsibility method. Researchers theorized that the sociocultural intervention was a novel idea to the traditional women, whereas the nontraditional women already were aware of the cultural pressures and believed there would be no immediate changes in the unrealistic images and expectations of women's physical appearance. The researchers suggested that further assessment is needed to determine the effectiveness of different interventions for women with different cognitive schemas, such as traditional or feminist ideologies (Glidden \& Tracey, 1989).

Glidden and Tracy (1989) are not the only researchers to propose differences between traditional and nontraditional women. Several studies have focused on body image, disordered eating, gender roles, and feminist ideology. Bem introduced the 
concept of measuring gender roles in 1974, but how these roles relate to body image and eating symptomatology still is unclear. Jackson, Sullivan, and Rostker (1988) found that while masculine women may be unsatisfied with their appearance, it is unimportant to them, and androgynous women report that their appearance is important, but they rate it favorably. Unfortunately, not only are feminine women unhappy with their appearance, but they also rate appearance as inherently more important than other women do (Timko, Streigel-Moore, Silberstein, \& Rodin, 1987). Davis, Dionne, and Lazarus (1996) found that as females' masculine characteristics increased so did body esteem. Similarly, Kimlicka, Cross, and Tarnai (1983) found that masculine and androgynous women had greater self-esteem, body satisfaction, and sexual satisfaction than feminine women. Interestingly, women who placed importance on or wished to possess more traditionally masculine characteristics reported the most disordered body shape concerns and eating disorder symptomatology of all the participants (Johnson \& Petrie, 1995; Timko et al., 1987).

Studies examining the relationship between gender type and disordered eating have resulted in mixed outcomes. Katzman and Wolchik (1984) found no gender role differences among undergraduate females who met the criteria for bulimia or binge eating disorder, as compared to those who did not. A meta-analysis conducted by Murnen and Smolak (1997) found that women with eating disorder symptomatology scored lower on scales measuring characteristics of masculinity and higher on measures of femininity. Traditional femininity in women also is associated with increased conformity, low selfperception of personal appearance and greater importance placed on physical appearance, thinness, lower self-esteem, less life satisfaction, and increased dietary restraint as 
compared to nontraditional women (Burger, 1987; Kleinplatz, McCarrey, \& Kateb, 1992; Hawkins, Turell, \& Jackson, 1983; Jackson et al., 1988; Streigel-Moore, Silberstein, \& Rodin, 1986; Timko et al., 1987; Whiteley, 1983). Perhaps, feminine women recognize that masculine characteristics are socially advantageous, whereas their feminine characteristics generally are not. Discomfort between how they perceive themselves and the characteristics they would like to possess may lead to a lack of self-esteem and heightened sensitivity to negative body image.

Given that research findings suggest that nonfeminine gender typed women typically are physically and mentally healthier than feminine women, it is conceivable that "nontraditional" women who possess primarily masculine characteristics or traits of both genders (i.e., androgynous) may be feminists whose cognitive schemas regarding beauty and women's roles lead to healthier body image and self-esteem. While some studies have found no relationship between a personal feminist ideology and disordered eating or negative body esteem (Mintz \& Betz, 1986; Xinaris \& Boland, 1990), others have found a significant relationship (Cash, Ancis, \& Strachan, 1997; Dionne, Davis, Fox, \& Gurevich, 1995; Snyder \& Hasbrouck, 1996). Dionne and colleagues (1995) found that women's feminist attitudes regarding physical attractiveness were correlated positively with body satisfaction, although overall feminist identification was not correlated with being more satisfied with one's body. Snyder and Hasbrouck (1996) found that, although masculine personality characteristics were unrelated to body dissatisfaction, drive for thinness, or bulimic symptomatology, women who identified with feminist values had significantly greater body satisfaction and less drive for thinness than women who did not. Therefore, regardless of gender role identification, feminist 
women reported better body image and less disordered eating than nonfeminists. In contrast, Cash and colleagues (1997) found no differences in body image between feminist and nonfeminist women. However, women with more stereotypical views of men and women, traditional beliefs regarding women's sexuality, a desire for traditional female and male interactions (i.e. aggressive male and submissive female), and harmful beliefs regarding the importance of one's appearance were more invested in their appearance and internalized the beauty ideal to a greater extent than women with less traditional views.

These findings suggest that women who adhere to feminist theories may experience less eating and body image disturbance and for a decade, researchers have emphasized the need to implement feminist theory in the treatment of body image and eating disorder disturbance (Fallon et al., 1994; Mason \& Chaney, 1996; Piran, 1995; Thompson, et al., 1999). In general, there are three feminist theories regarding body image: Culture of Thinness, Weight as Power and Control, and Anxieties About Female Appearance-Achievement (Thompson, Heinberg, Altabe, \& Tantleff-Dunn, 1999). The Culture of Thinness focuses on beauty ideals for women that are mostly communicated through the media (Thompson et al., 1999). The theory proposes that body image and eating disturbance are reactions to societal messages that women need to be thin in order to be accepted and loved (Thompson et al., 1999). This is supported by a great deal of research that shows prototypical beauty has become thinner, with average weights for women in Miss America pageants and Playboy magazine stabilizing around 13 to 19\% below recommended height and weight ratios (Wiseman, Gray, Mosimann, \& Ahrens, 1992). As these weights have decreased, rates of eating disorders have increased 
(Wiseman et al., 1992). The notion of Weight as Power and Control asserts that historically women have had no jurisdiction over their bodies and possessions and consequently experience this needed control through dieting or overeating (Thompson et al., 1999). Although this theory has not been extensively empirically supported, the proposed relationship between sexual abuse and eating disturbance lends credence to the premise (Smolak \& Murnen, 2002). Women who experience the ultimate loss of control over their bodies may be more likely to develop disordered eating. Lastly, Anxieties About Female Appearance -Achievement theorizes that body image and eating disturbance allows females to refute womanhood and success by returning to or keeping a prepubescent body that takes up less space, is nonthreatening, and is "sufficiently feminine" (Thompson et al., 1999, p. 221). This theory is twofold: First, eating disturbance allows women to be successful yet not threatening within typically masculine sects of professions (Thompson et. al., 1999). Second, the refutation of the female form may be viewed as a way to ensure safety from harassment and violation (Thompson et al., 1999). Evidence suggests that in periods of high stress, such as college graduation, women experience an increase in disordered eating (Perlick \& Silverstein, 1994). This may be a way that women thwart their own chances of success. This assumption, however, has been called into question, due to confounding variables such as women attending college in increasing numbers (Gilbert \& Thompson, 1996). An increase in the population of women in college may artificially enlarge the occurrence of disturbed eating.

These three feminist theories of body image have modest empirical and anecdotal support, but they never have been tested as an intervention or prevention method (Gilbert 
\& Thompson, 1996). The majority of previous body image and eating disorder interventions have been psychoeducational programs based on the sociocultural theory of body image disturbance (Stormer, 1999) that asserts body image and eating disturbance are the byproduct of an appearance-obsessed society. The three feminist theories of disturbance are similar to sociocultural theory in that all view the disorders as a result of external pressures, not personal psychopathology.

This external view is a key aspect of the feminist theories of eating disturbance. The way in which women perceive external appearance-related pressures and messages may alter the subsequent impact on their body image. Glidden and Tracey (1989) theorized that feminist women recognized that external pressures to achieve the thin-ideal are not going to change in the near future, thus one may need to change the way she views and interprets these messages. This is a key component in Cognitive Behavioral Therapy (CBT), an effective treatment approach to many disorders, including eating disorders (Fairburn, Jones, Peveler, Hope, \& O’Connor, 1993; Fairburn, Norman, Welch, \& O'Connor, 1995). The theory of CBT is that people interpret messages in a way that contributes to the development of their disorders (Beck, 1995). CBT focuses on identifying each maladaptive thought, checking the evidence that either supports or refutes the thought, and replacing it with a healthier cognition (Beck, 1995). Each message is filtered through this type of reality check designed to interpret the world in a more realistic and healthy manner.

This reality check may be what feminists have been doing all along to deter body image disturbance. Feminist women are exposed to many of the same messages as their nonfeminist counterparts. Lull, Mulac, and Rosen (1983) found that feminist and 
nonfeminists with "some" college education watched similar amounts of television, yet feminists had healthier self-esteem and body image. Similar to CBT, a feminist schema may work as a buffer - a filter through which cultural messages about thinness and beauty are challenged rather than passively accepted. A feminist schema may provide an alternative interpretation of cultural messages such that feminists may not perceive personal deficiencies because they do not resemble the women portrayed in the media. Unlike CBT, exposure to feminist theories of body image may offer individuals a healthier means to interpret all appearance-related messages, rather than focus on individual negative cognitions.

Interventions utilizing sociocultural theory have shown women that societal messages regarding beauty are unhealthy and unrealistic. The information provided and potential impact, however, are limited. The intervention informs participants that images presented are not accurate, but does not offer them an adaptive way of interpreting the plethora of messages about weight and shape that women experience everyday. A feminist schema may empower women to critically and accurately assess the onslaught of harmful messages. In fact, empirical evidence demonstrates that women with feminist schemas are less likely to experience body image dissatisfaction and disordered eating (Cash et al., 1997; Dionne et al., 1995; Snyder \& Hasbrouck, 1996).

In summary, previous research has shown that long-term psychoeducational interventions (i.e., a semester length college class) focusing on the media and sociocultural theories of body image may work effectively to reduce symptomatology (Springer et al., 1999; Stice \& Ragan, 2002). This type of intervention, however, may not provide women with a broader viewpoint through which to filter all of society's 
harmful appearance-related messages. Due to the serious consequences and wide spread nature of body image and eating disturbance, development and empirical validation of effective intervention methods is needed (Stice et al., 2001).

This study sought to determine if exposure to feminist theory may create or enhance a feminist schema, thereby enabling women to filter society's harmful and unrealistic messages regarding weight and shape. This schema is theorized to decrease body image and eating disturbance and increase empowerment and self-esteem when compared to a traditional psychoeducational intervention or control group. Based on previous research that demonstrated a relationship between disordered body image and eating symptomatology and factors such as sex role and feminist identification, these factors will be investigated within the context of the interventions (Glidden \& Tracy, 1989). It was hypothesized that, regardless of these factors (i.e., sex role or preintervention feminist identification), that participants exposed to the feminist theory intervention would experience an increase in feminist schema and significant improvements in body image and eating symptomatology, empowerment, and selfesteem. Further, participants who report the greatest pre-intervention eating disturbance will benefit most from the feminist condition when compared to participants without elevated symptoms. Participants in the psychoeducational and control conditions were not hypothesized to experience significant changes in feminist schema, body image or eating disturbance, empowerment, or self-esteem. 


\section{METHOD}

\section{$\underline{\text { Participants }}$}

Based on the modest findings of intervention studies, the estimated effect size chosen was .50 and the suggested power was .80 . For this, Cohen (2003) suggests a sample size of 156 (i.e., 52 participants in each of the intervention groups). Two hundred and ninety-seven women were recruited from undergraduate classes at a large southeastern university and offered extra credit for completing the study. Of the 297 that completed the first set of questionnaires, approximately 200 signed up for the second portion of the study (i.e., presented as a separate and unrelated study). Of those who agreed to participate, 161 completed both portions of the study. In total, 29 participants' data was excluded from the analyses (see Results section) resulting in a final sample size of 131 participants. Their mean age was $20.24(\mathrm{SD}=1.88)$, and they were of the following ethnicities: Caucasian $=65.6 \%$, Hispanic $/$ Latino $=17.6 \%$, African American $=9.2 \%$, Asian $=3.1 \%$, and $4.6 \%$ identified as "Other." The majority of the participants identified themselves as heterosexual (98.5\%), 1 person reported being homosexual, and 1 person reported being bisexual (See Table 1 for further demographic breakdown).

\section{$\underline{\text { Measures }}$}

Feminist Identity Composite (FIC; Fischer, Good, \& Hill, 2000, see Appendix A). This scale is a combination of the Feminist Identity Development Scale (FIDS; Bargad \& Hyde, 1991) and the Feminist Identity Scale (FIS; Rickard, 1987). Using factor analyses, Fischer and colleagues (2000) utilized 14 items from the FIDS and 20 from the FIS to create the FIC. This measure was validated on female community and student samples. Participants are assessed on five theorized stages of feminist identity: Passive 
Acceptance, Revelation, Embeddedness, Synthesis, and Active Commitment. Reported internal consistency estimates (Cronbach's alpha) were $.74, .75, .86, .71$, and .81 , respectively.

Empowerment Scale (ES; Rogers, Chamberlin, Ellison, \& Crean, 1997, see Appendix B). This is a 28 -item scale that measures the construct of empowerment for consumers of mental health services. The measure consists of five factors: selfesteem/self-efficacy, power/powerlessness, community activism and autonomy, optimism and control over the future, and righteous anger. Answers are based on a Likert scale. Cronbach's alpha was .86 and the measure correlated positively with measures of community involvement, quality of life, social support, and self-esteem.

Bem Sex Role Inventory (BSRI; Bem, 1974, see Appendix C). The BSRI is a measure of stereotypic gender personality characteristics. The measure contains 60 -items that are answered on a Likert scale. The internal consistency of this measure is high with alphas of $.86, .80$, and .85 for the Masculinity, Femininity, and Androgyny scales respectively. Test-retest reliability ranged from $.90-.93$ after a four-week follow-up.

Sociocultural Attitudes Toward Appearance Questionnaire (SATAQ; Heinberg, Thompson, \& Stormer, 1995, see Appendix D). The SATAQ is a 14-item scale that assesses the extent to which women are aware of and believe in societal standards of beauty. Participants answer questions based on a 5-point Likert scale (i.e., completely disagree to completely agree). The SATAQ includes two subscales, Internalization $($ alpha $=.88)$ and Awareness $($ alpha $=.71)$. The SATAQ correlates significantly with many measures of eating symptomology (e.g. Eating Disorders Inventory; Heinberg et al., 1995). 
Multidimensional Body Self-Relations Questionnaire (MBSRQ; Brown, Cash, \& Mikulka, 1990, see Appendix E). The MBSRQ is a 69-item scale that measures multiple aspects of body image disturbance. Two subscales will be used in this study: Appearance Evaluation subscale (MBSRQ-AE) and the Body Areas Satisfaction subscale (MBSRQ$\mathrm{BAS})$. The AE is a seven-item scale that provides a personal evaluation of aspects of physical appearance such as "I am physically attractive." The BAS, a nine-item scale, measures satisfaction with different body sites (e.g., face, mid torso, weight). Participants respond using a 5-point Likert scale (i.e., definitely disagree to definitely agree). Internal consistency for the $\mathrm{AE}$ is .88 and the $\mathrm{BAS}$ is .73. At a one-month follow-up, test retest reliability was .91 and .73 , respectively.

Physical Appearance State and Trait Anxiety Scale (PASTAS; Reed, Thompson, Brannick, \& Sacco, 1991, see Appendix F). The PASTAS is a self-report measure of state and trait anxiety for eight weight-related (e.g., thighs, hips) and eight non-weightrelated (e.g., ears, lips) body sites. For this study the trait scale was used. Participants rate how often they generally experience tension or anxiety about their body sites on a 5point Likert scale (i.e., never to almost always). Reported Cronbach's alphas for both weight and non-weight scales ranged from .82 to .92 , and test-retest reliability was .82 . Appearance Schema Inventory (ASI; Cash \& Labarge, 1996, see Appendix G). This is a 14-item scale designed to assess core beliefs or assumptions about the importance, meaning, and effects of appearance in one's life. The internal consistency is .84. Factor analysis suggested three moderately interrelated components of the ASI body-image vulnerability, self-investment, and appearance stereotyping. 
The Self-Esteem Inventory (SEI; Rosenberg, 1965, see Appendix H). This 10-item scale measures self-esteem. Rosenberg (1965) reported a reliability coefficient of .92, test-retest reliability of .85 , and convergent validities were $.56, .67$, and .83 , with three other measures of self-esteem. The SEI has been negatively correlated with body size overestimation (Thompson \& Thompson 1986).

Eating Disorders Inventory - II (Garner, 1991, Appendix I). The EDI - II (Garner, Olmstead, \& Polivy, 1983; Garner, 1991) is a self-report measure of attitudes, feelings, and behavior regarding disordered eating. For this study, the Body Dissatisfaction subscale will be used, which measures the overall dissatisfaction with size and shape of specific body parts (i.e., stomach, hips). Participants respond using a 6point Likert scale (never to always). Internal consistency has been found to range from .91 to 93 . Test-retest reliability was .95 at one week, .97 at three weeks, and .75 at one year.

Visual Analogue Scale (VAS, see Appendix J). The VAS is a self-report measure designed to assess changes in areas of body image satisfaction. They are comprised of lines (typically 10 centimeters in length), and at each endpoint is the opposite view for the construct being measured (e.g., "no dissatisfaction with appearance" to "dissatisfaction with appearance as bad as it could be," Stormer, 1999). Participants make a vertical mark through the line to indicate their response (e.g., from "not at all invested" to "completely invested") to statements such as "Investment in my physical appearance." There were 6 VAS questions that asked participants to rate items such as "Satisfaction with my physical appearance" and "Sexual appeal of my physical appearance." This measure is used as a supplement to traditional Likert scales that may 
restrict the range of responses and may be more subject to testing effects. Heinberg and Thompson (1995) found several VAS measures to be correlated significantly with the EDI-Body Dissatisfaction Scale.

Contour Drawing Rating Scale (CDRS; Thompson \& Gray, 1995, see Appendix $K)$. The measure consists of drawings depicting women and men from a range of extremely underweight to obese. Test-retest reliability of self-ratings were within the acceptable range $(r=.87)$. Validity was shown through a $97-98 \%$ accuracy rate in ordering the drawings from thinnest to heaviest. Additionally, the most anorexic and obese drawings were correctly identified $96 \%$ (male-anorexic), 98\% (female-anorexic), $88 \%$ (male-obese), and $90 \%$ (female-obese) of the time. The measure asks participants to choose their ideal body size.

Eating Attitudes Test (EAT; Garner \& Garfinkel, 1979, see Appendix L). The EAT is a self-report measure designed to assess disordered eating habits. Participants respond to 40 items (i.e., "give too much time and thought to food") on a 6-point Likert scale (i.e., never to always). This measure has adequate validity, reliability (alpha $=.79$ and .94), and the ability to discriminate between clinical and nonclinical populations.

\section{$\underline{\text { Procedure }}$}

\section{Time 1}

Female participants were asked to complete a packet of surveys containing measures of demographic information, body image and eating disturbance, empowerment, self-esteem, sex role orientation, and feminism. Upon completion, participants were offered the chance to sign up for another study. To decrease participant biases, the second part of the study was presented as a separate study from the first. 
Time 2

Women were randomly assigned to one of three conditions. The two intervention conditions involved listening to one of two 15-minute audiotapes created for this study: feminist or psychoeducational. Each tape was recorded by a female narrator with a pleasant speaking voice and was accompanied by a packet of images that corresponded with the oral presentation. Audiotapes were chosen to eliminate the appearance of the presenter as a confounding variable. In groups of one to six, participants listened to the tapes through personal headsets, separated from each other with dividers to ensure privacy and confidentiality. The third condition served as a control and participants were not exposed to an intervention at Time 2 .

\section{Condition 1: Feminist Theory Intervention (FTI)}

This audiotape focused on feminist theories of body image and eating disturbance (i.e. Culture of Thinness, Weight as Power and Control, and Anxieties About Female Appearance-Achievement). The FTI began with definitions and an explanation of feminism. Subsequently, each theory, its background, and corresponding empirical research was discussed in detail. For example, Mintz and Betz's (1986) findings that women who abide by society's ideals of beauty are more likely to experience disordered eating was presented. Pictures in the corresponding visual packet included images such as historical photos of the women's movement and art such as Degas' Bather (see Appendix $\mathrm{M}$ for transcript and $\mathrm{N}$ for example image).

\section{Condition 2: Psychoeducational Intervention (PI)}

To replicate past psychoeducational interventions and also to serve as a comparison to the FTI, participants listened to an audiotape that described the 
sociocultural theory of body image and eating disorders. Topics included the unrealistic bodies of models and the use of airbrushing to change the appearance and shape of women in magazines. For example, the fact that the average woman is 5 foot 4 inches tall and weighs 142 pounds, whereas the average model is 5 foot 9 inches tall and weighs 110 pounds was presented. Pictures in the corresponding visual packet included examples of computer alteration of pictures and runway models (see Appendix O for transcript and $\mathrm{P}$ for example image).

\section{Condition 3: Assessment Only Control (AOC)}

This group served as a temporal control to determine if changes in symptomatology occurred naturally, without intervention. Participants in this group were not exposed to an intervention and completed the same post test packet of measures as the FTI and PI conditions.

\section{Post Test}

Following exposure, participants in the FTI and PI conditions were asked to complete a quiz that served as a manipulation check. Participants who answered more than one quiz question incorrectly were excluded from the analyses (Lavin \& Cash, 2001). One question for the FTI was not included in this exclusion criterion because more than $50 \%$ of the participants answered it incorrectly. Participants rated the PI and FTI as equally interesting, providing new information, and influential on their attitudes and/or beliefs regarding body image and eating disturbance. The quiz for the FTI was rated as significantly harder, $\mathrm{F}(1,92)=10.37, \mathrm{p}=.002$, however, participants in the FTI and PI correctly answered the quiz questions at an average of $89.73 \%$ and $85.71 \%$, respectively. Following the quiz, participants were asked to complete the same packet of 
measures as completed at Time 1. Participants in the AOC completed the same packet with the exclusion of the quiz. 


\section{RESULTS}

Of the 161 participants who participated in Time 1 and Time 2 (i.e., Feminist Condition $=57$, Psychoeducational Condition $=53$, Control Condition $=51$, four participants' information was excluded from the analyses due to an unstandardized administration of the intervention (i.e., food was placed in the intervention room prior to administration and not taken out), 15 participants were excluded due to extreme outlier scores, and 11 participants were excluded because they answered more than one question wrong on the aforementioned quiz. The final sample size included 131 participants (i.e., Feminist Condition $=43$, Psychoeducational Condition $=46$, Control Condition $=42$ )

All variables were screened for skewness, kurtosis, outliers, normality using the Kolmogorov-Smirnov test, and homogeneity of variance using Levene's test. There were no variables in which both non-normality of distribution and unequal variance were a problem, suggesting no major violations in statistical assumptions underlying the parametric statistics used (Keppel \& Zedeck, 1998, p. 108). Based on one-way ANOVAS and chi-square analyses, there were no significant differences on measures of demographics (see Table 1), Body Mass Index (BMI), self-esteem, feminism, empowerment, or disturbance among the FTI, PI, and AOC groups at Time 1, and there was no significant change in BMI from Time 1 to Time 2 across all groups.

Chi-square analyses were conducted on the Yes or No responses to the question, "Do you consider yourself a feminist?" While not significant at Time 1, there were significant differences among groups at Time 2. At Time 2, participants in the FTI were significantly more likely to identify themselves as a feminist when compared to the PI, $\chi^{2}$ 
$(1)=4.53, p=.021$ and AOC, $\chi^{2}(1)=11.21, p=.001$. There were no significant differences between the PI and AOC, $\chi^{2}(1)=1.44, p=.23$ (see Table 1). 
Table 1: Participants' demographic information at Time 1

\begin{tabular}{llll}
\hline Measure & FTI & PI & AOC
\end{tabular}

\begin{tabular}{llll}
\hline Age $X(S D)$ & $20.02(1.54)$ & $20.24(1.82)$ & $20.45(2.25)$
\end{tabular}

Body Mass $X(S D)$

$23.30(5.95) \quad 22.06(3.45) \quad 23.17(5.04)$

Ethnicity

$\begin{array}{lccc}\text { Caucasian } & 65.1 \% & 63.0 \% & 69.0 \% \\ \text { Hispanic/Latino } & 18.6 \% & 23.9 \% & 9.5 \% \\ \text { African American } & 9.3 \% & 8.7 \% & 9.5 \% \\ \text { Asian } & 4.7 \% & 0 \% & 4.8 \% \\ \text { Others } & 2.3 \% & 4.3 \% & 7.1 \%\end{array}$

Sexual Orientation

$\begin{array}{lccc}\text { Heterosexual } & 100.0 \% & 100.0 \% & 95.8 \% \\ \text { Homosexual } & 0 \% & 0 \% & 2.4 \% \\ \text { Bisexual } & 0 \% & 0 \% & 2.4 \%\end{array}$

Taken a women's studies

class?
Yes
$25.6 \%$
$17.4 \%$
$14.3 \%$

Consider yourself a feminist?

$\begin{array}{rrrr}\text { Yes Time 1 } & 52.4 \% & 48.9 \% & 39.5 \% \\ \text { Time 2 } & 69.0 \% & 43.4 \% & 31.6 \%\end{array}$


Repeated measures ANOVAS were conducted to examine changes in measures of body image and eating disturbance, empowerment, self-esteem, and feminism from Time 1 to Time 2 as a function of Condition (see Tables $2-7$ ). A Bonferroni correction was used to decrease the chance of a Type 1 error. A starting alpha of .05 was divided by 5 (i.e., the number of variable categories) resulting in a modified alpha level of .01. There were significant main effects for time on the Active Commitment subscale of the FIC scale, $F(2,128)=13.21, p<.0005$, ideal female figure of the CDRS, $F(2,128)=20.66$, $p<.0005$, Appearance Evaluation subscale of the MBSRQ, $F(2,126)=7.166, p=.008$, and Righteous Anger subscale of the ES, $F(2,123)=7.33, p<.008$. These results indicate that significant changes occurred across all groups from Time 1 to Time 2.

There was a significant Condition by Time interaction on self-identification as a feminist, $F(2,128)=5.41, p=.006$ (see Table 6). Post-hoc pairwise comparisons were then conducted, with a new adjusted alpha level of .017 (i.e., corrected for 3 comparisons). Results indicate that participants in the FTI experienced significant increases in self-identification as a feminist from Time 1 to Time 2 when compared to the AOC, $F(1,83)=6.25, p=.014$ and PI, $F(1,87)=8.76, p=.004$. The FTI led to the following effect sizes when compared to the PI, Cohen's $d=.47$, and AOC, Cohen's $d=$ .56. These effect sizes indicate that approximately $69 \%$ of the feminism scores for the FTI participants would be expected to fall above the mean score of the PI and $73 \%$ of the FTI scores would fall above the mean of the AOC (see Figure 1). There were no significant differences when comparing the PI to the AOC, $F(1,86)=.71, p=.402$ (Cohen's $d=.09$; see Tables $8-9$ ). 
There was a Condition by Time trend for the VAS measure: "Satisfaction with my physical appearance," $F(2,125)=3.99, p=.021$ (see Table 2 ). Due to the exploratory nature of this study, further post-hoc pairwise comparisons were conducted, with a new adjusted alpha level of .017 (i.e., corrected for 3 comparisons). Results indicate that participants in the FTI experienced significant increases in physical appearance satisfaction from Time to Time 2 when compared to the AOC, $F(1,81)=7.34, p=.008$ but not the PI, $F(1,85)=4.90, p=.030$. The FTI led to the following effect sizes when compared to the PI, Cohen's $d=.23$, and AOC, Cohen's $d=.19$. These effect sizes indicate that approximately $58 \%$ of the physical appearance scores for the FTI participants would be expected to fall above the mean score of the PI and $23 \%$ of the FTI scores would fall above the mean of the AOC (see Figure 2). There were no significant differences when comparing the PI to the AOC, $F(1,84)=.192, p=.663$ (Cohen's $d=$ .01 ; see Tables $8-9)$. 
Table 2: Time by condition repeated measures ANOVAS for the Visual Analogue Scale

\begin{tabular}{llllll}
\hline Measure & FTI & PI & AOC & $F(1,126)$ & $p$
\end{tabular}

$X(S D) \quad X(S D) \quad X(S D)$

Satisfaction with PA

$\begin{array}{llllll}\text { Time } 1 & 5.27(1.81) & 5.59(2.02) & 5.74(2.03) & & \\ \text { Time 2 } & 6.11(1.72) & 5.76(1.69) & 5.77(1.73) & 3.994 & .021\end{array}$

Investment in PA

$\begin{array}{llllll}\text { Time } 1 & 5.30(1.98) & 5.40(1.94) & 5.01(2.06) & & \\ \text { Time 2 } & 5.60(2.01) & 5.36(1.85) & 5.39(1.56) & .597 & .552\end{array}$

The importance of PA

$\begin{array}{lllllll}\text { Time 1 } & 6.24(1.76) & 6.27(1.67) & 6.48(1.68) & & \\ \text { Time 2 } & 6.32(1.31) & 6.13(1.32) & 6.46(1.78) & .226 & .798\end{array}$

Anxiety regarding PA

$\begin{array}{llllll}\text { Time } 1 & 4.66(2.43) & 4.49(1.89) & 4.27(2.35) & & \\ \text { Time 2 } & 4.82(2.29) & 4.70(2.07) & 4.53(2.00) & .038 & .962\end{array}$

LS is based on PA
Time 1
$4.09(1.83) \quad 3.78(1.82) \quad 3.80(2.16)$
Time 2
$4.07(1.61) \quad 3.84(1.84) \quad 4.43(1.94)$
$1.900 \quad .154$

Sexual appeal of PA
Time 1
$5.23(2.10) \quad 5.31(1.94) \quad 5.78(1.68)$
Time 2
$5.43(1.70) \quad 5.60(1.76) \quad 6.01(1.46)$
.028
.972

Note. $\mathrm{PA}=$ Physical appearance. $\mathrm{LS}=$ Life Satisfaction. 
Table 3: Time by condition repeated measures ANOVAS for measures of eating and body image disturbance

\begin{tabular}{|c|c|c|c|c|c|}
\hline \multirow[t]{2}{*}{ Measure } & FTI & PI & $\mathrm{AOC}$ & $F(1,126)$ & $p$ \\
\hline & $X(S D)$ & $X(S D)$ & $X(S D)$ & & \\
\hline \multicolumn{6}{|l|}{ EAT } \\
\hline Time 1 & $54.98(23.69)$ & $61.13(18.54)$ & $52.46(13.74)$ & & \\
\hline Time 2 & $54.72(24.61)$ & $58.22(21.50)$ & $52.17(16.30)$ & 1.531 & .220 \\
\hline \multicolumn{6}{|l|}{ EDI } \\
\hline Time 1 & $29.19(8.44)$ & $31.13(8.86)$ & $27.60(9.31)$ & & \\
\hline Time 2 & $28.53(9.60)$ & $31.22(9.210$ & $27.74(9.80)$ & .379 & .685 \\
\hline \multicolumn{6}{|l|}{ CDRS } \\
\hline Time 1 & $3.65(1.21)$ & $3.86(1.01)$ & $4.13(1.11)$ & & \\
\hline Time 2 & $3.94(1.56)$ & $4.34(1.08)$ & $4.36(.91)$ & 1.095 & .338 \\
\hline
\end{tabular}

\section{PASTAS}

Weight

related

Time $1 \quad 14.61(5.58) \quad 15.64(5.07) \quad 13.92(6.04)$

Time $2 \quad 14.00(5.97) \quad 14.96(5.12) \quad 13.67(6.03) \quad .186$

.831

Non-weight

Time $1 \quad 3.81(3.83) \quad 3.47(2.81) \quad 4.07(3.98)$

$\begin{array}{llllll}\text { Time } 2 & 3.37(3.32) & 3.27(3.18) & 3.34(3.02) & .398 & .672\end{array}$

Note. EAT $=$ Eating Attitudes Test. CDRS $=$ Contour Drawing Rating Scale. PASTAS $=$ Physical Appearance State and Trait Anxiety Scale. EDI = Eating Disorders Inventory. 
Table 4: Time by condition repeated measures ANOVAS for measures of body image disturbance

\begin{tabular}{llllll}
\hline Measure & FTI & PI & AOC & $F(1,126)$ & $p$ \\
& $X(S D)$ & $X(S D)$ & $X(S D)$ & & \\
& & & & & \\
\hline
\end{tabular}

ASI

BIV

Time $1 \quad 14.65(4.46) \quad 16.46(4.59) \quad 14.40(4.24)$

$\begin{array}{llllll}\text { Time } 2 & 14.86(4.28) & 15.52(4.13) & 15.19(4.55) & 5.15 & .007\end{array}$

SI

Time $1 \quad 13.33(3.62) \quad 13.89(3.03) \quad 14.17(3.2)$

$\begin{array}{llllll}\text { Time } 2 & 12.86(3.06) & 13.35(3.27) & 14.26(3.36) & .796 & .454\end{array}$

AS

Time $1 \quad 6.09(2.44) \quad 6.26(2.16) \quad 6.41(2.28)$

$\begin{array}{llllll}\text { Time } 2 & 6.42(2.25) & 6.32(2.01) & 6.63(2.38) & .235 & .791\end{array}$

MBSRQ

$\mathrm{AE}$

Time $1 \quad 24.29(5.57) \quad 22.80(6.04) \quad 25.45(4.95)$

$\begin{array}{llllll}\text { Time } 2 & 25.00(5.35) & 24.28(5.79) & 25.50(4.99) & 2.269 & .108\end{array}$

BAS

Time $1 \quad 30.53(5.85) \quad 30.00(5.00) \quad 32.24(5.69)$

$\begin{array}{llllll}\text { Time } 2 & 31.41(6.00) & 31.00(5.23) & 32.49(6.08) & .557 & .575\end{array}$

Note. ASI = Appearance Stereotyping Inventory. BIV = Body-image vulnerability. SI = Self-investment. $\mathrm{AS}=$ Appearance stereotyping . MBSRQ $=$ Multidimensional Body Self-Relations Questionnaire. AE $=$ Appearance evaluation. BAS $=$ Body areas satisfaction. 
Table 5: Time by condition repeated measures ANOVAS for measures of body image disturbance and self-esteem

\begin{tabular}{llllll}
\hline Measure & FTI & PI & AOC & $F(1,126)$ & $p$ \\
& $X(S D)$ & $X(S D)$ & $X(S D)$ & & \\
\hline
\end{tabular}

SATAQ

Internalization

Time $1 \quad 23.16(7.79) \quad 25.76(7.14) \quad 24.34(6.49)$

Time 2

$24.24(7.14) \quad 26.31(7.36) \quad 23.44(7.23) \quad 2.53$

.084

Awareness

$\begin{array}{llll}\text { Time } 1 & 19.39(2.80) & 19.80(2.81) & 19.74(3.25)\end{array}$

$\begin{array}{llllll}\text { Time } 2 & 19.72(2.95) & 19.60(3.00) & 20.38(2.90) & .916 & .403\end{array}$

SEI

Time $1 \quad 32.99(4.02) \quad 33.21(4.59) \quad 33.68(4.05)$

Time 2

$33.29(4.20) \quad 34.26(4.58) \quad 33.98(4.08) \quad .777$

.462

Note. SATAQ = Sociocultural Attitudes Toward Appearance Questionnaire. SEI = Rosenberg Self Esteem Inventory. 
Table 6: Time by condition repeated measures ANOVAS for measures of feminism

\begin{tabular}{clllll}
\hline Measure & FTI & PI & AOC & $F(1,126)$ & $p$ \\
& $X(S D)$ & $X(S D)$ & $X(S D)$ & & \\
\hline Feminist self rating? $^{\mathrm{a}}$ & & & & & \\
Time 1 & $2.67(.87)$ & $2.63(.68)$ & $2.82(.79)$ & & \\
Time 2 & $2.33(.89)$ & $2.74(.77)$ & $2.81(.83)$ & 5.41 & .006
\end{tabular}

FIC

Passive acceptance

Time 1

$19.84(5.22) \quad 19.77(4.85) \quad 19.93(3.57)$

Time 2

$19.65(5.16)$

$19.82(4.68)$

$19.88(4.01) \quad .09$

.912

Revelation

Time 1

$18.70(6.00) \quad 20.27(4.95) \quad 18.79(4.72)$

Time 2

$19.19(5.45) \quad 20.28(5.32)$

$19.62(5.36) \quad .39$

.680

Embeddedness

Time 1

$12.72(3.40) \quad 12.87(3.76) \quad 12.67(3.07)$

Time 2

$12.90(3.13) \quad 12.30(4.17) \quad 12.31(3.13) \quad .93$

.399

Synthesis

Time 1

$23.28(2.98) \quad 22.82(3.05) \quad 23.19(2.85)$

Time 2

$23.56(2.64) \quad 23.13(3.14) \quad 22.76(2.82) \quad 1.25$

.291

Active commitment

Time 1

$32.42(5.50) \quad 31.74(5.59) \quad 31.86(3.78)$

Time 2

$31.21(5.59) \quad 30.52(5.49) \quad 30.93(4.81) \quad .09$

.911

Note. FIC $=$ Feminist Identity Composite $.{ }^{a}=$ Participants rated their level of feminism on a Likert scale (i.e., $1=$ very feminist to $5=$ very traditional). 
Table 7: Time by condition repeated measures ANOVAS for the empowerment scale

\begin{tabular}{|c|c|c|c|c|c|}
\hline \multirow[t]{2}{*}{ Measure } & FTI & PI & $\mathrm{AOC}$ & \multirow[t]{2}{*}{$F(1,126)$} & \multirow[t]{2}{*}{$p$} \\
\hline & $X(S D)$ & $X(S D)$ & $X(S D)$ & & \\
\hline \multicolumn{6}{|c|}{ Empowerment Scale } \\
\hline \multicolumn{6}{|c|}{ Self-esteem/efficacy } \\
\hline Time 1 & $26.62(3.57)$ & $29.98(3.43)$ & $29.47(3.30)$ & & \\
\hline Time 2 & $29.50(3.19)$ & $30.07(3.42)$ & $29.14(3.33)$ & .278 & .758 \\
\hline \multicolumn{6}{|c|}{ Powerlessness } \\
\hline Time 1 & $16.14(3.02)$ & $15.73(2.28)$ & $16.46(2.28)$ & & \\
\hline Time 2 & $15.60(2.73)$ & $15.58(2.13)$ & $16.51(2.12)$ & .867 & .423 \\
\hline \multicolumn{6}{|c|}{ Community activism } \\
\hline Time 1 & $20.17(2.19)$ & $20.45(1.82)$ & $20.20(2.03)$ & & \\
\hline Time 2 & $20.24(2.15)$ & $19.95(2.14)$ & $19.78(2.02)$ & 1.05 & .353 \\
\hline \multicolumn{6}{|l|}{ Optimism } \\
\hline Time 1 & $11.86(1.66)$ & $12.07(1.56)$ & $12.17(1.67)$ & & \\
\hline Time 2 & $12.16(1.54)$ & $12.11(1.65)$ & $12.07(1.57)$ & .718 & .490 \\
\hline \multicolumn{6}{|c|}{ Righteous anger } \\
\hline Time 1 & $8.93(1.79)$ & $8.93(1.35)$ & $8.92(1.47)$ & & \\
\hline Time 2 & $8.45(2.10)$ & $8.55(1.50)$ & $8.75(1.35)$ & .475 & .623 \\
\hline
\end{tabular}




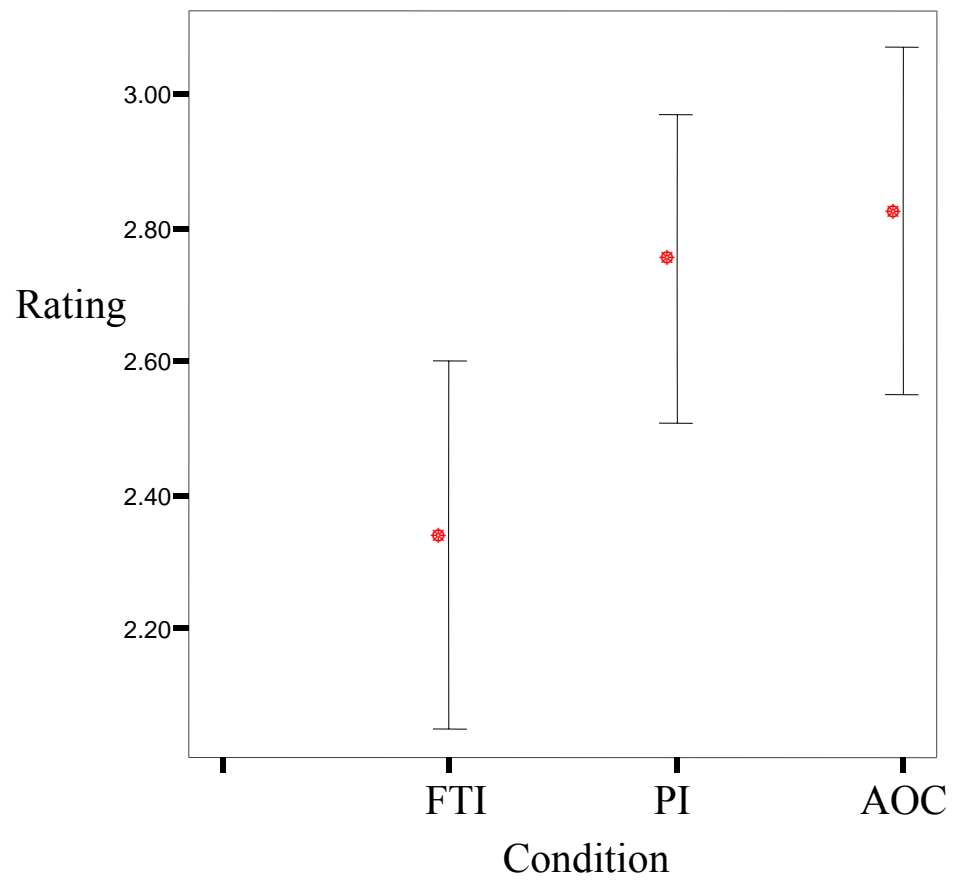

Figure 1: Means and confidence intervals for feminist self-rating scores by condition. 
Table 8: Reported effect sizes

\begin{tabular}{lll}
\hline & PI & AOC \\
\hline FTI & .47 & .56 \\
VEM & .23 & .19 \\
BIV & .01 & .07 \\
PI & & \\
FEM & - & .09 \\
VAS1 & - & .01 \\
BIV & - & .08
\end{tabular}

Note. FEM = Feminist self-rating; VAS1 = physical appearance satisfaction rating; BIV = Body Image Vulnerability.

Table 9: Confidence intervals for reported effect sizes

\begin{tabular}{|c|c|c|c|}
\hline & FTI & PI & $\mathrm{AOC}$ \\
\hline & $X(\mathrm{CI})$ & $X(\mathrm{CI})$ & $X(\mathrm{CI})$ \\
\hline Feminist Rating & $2.33(2.05-2.60)$ & $2.74(2.51-2.97)$ & $2.81(2.55-3.07)$ \\
\hline VAS 1 & $6.11(5.57-6.65)$ & $5.76(5.25-6.27)$ & $5.77(5.23-6.32)$ \\
\hline BIV & $14.86(13.54-16.18)$ & $15.52 \quad(14.29-16.75)$ & $15.19(13.77-16.61)$ \\
\hline
\end{tabular}

\footnotetext{
Note. $\mathrm{CI}=95 \%$ confidence interval. VAS $1=$ measure of physical appearance satisfaction. $\mathrm{BIV}=\mathrm{Body}$ Image Vulnerability Scale.
} 


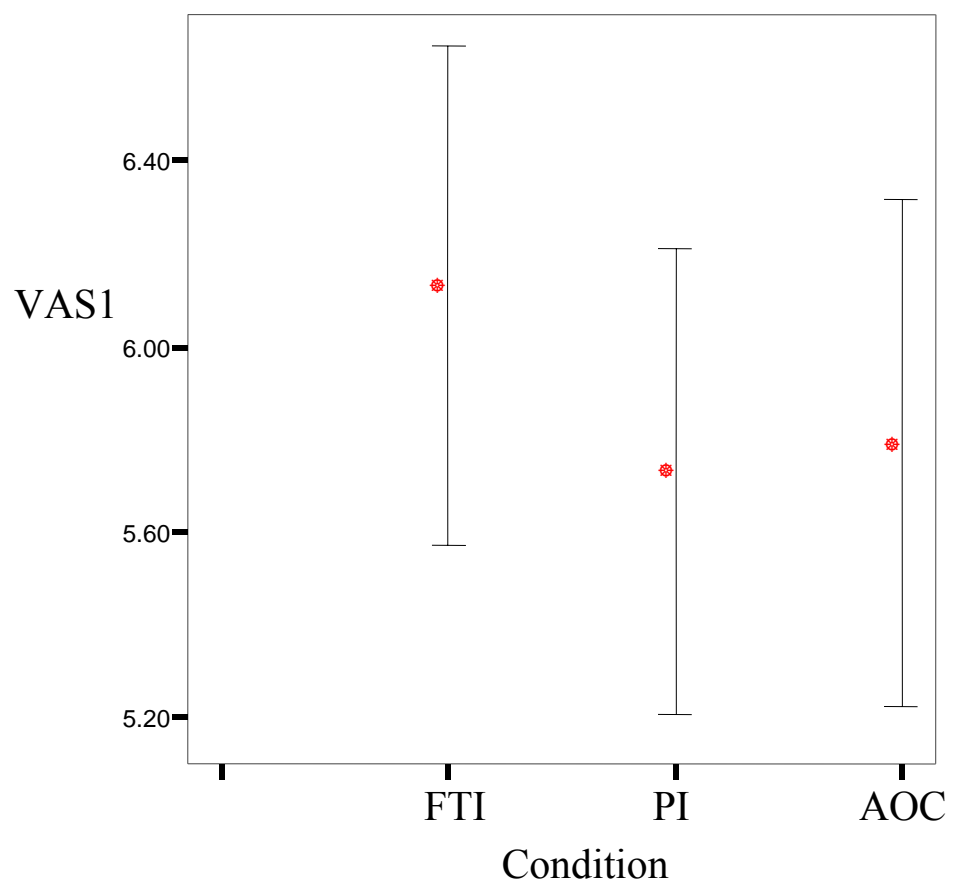

Figure 2: Mean and confidence intervals for physical appearance satisfaction scores by condition.

There was a significant Condition by Time interaction on the ASI-Body Image Vulnerability (BIV) subscale, $F(2,128)=5.15, p=.007$ (see Table 4). Post-hoc pairwise comparisons were then conducted, with a new adjusted alpha level of .017 (i.e., corrected for 3 comparisons). Results indicate that the PI significantly decreased BIV from Time 1 to Time 2 when compared to the AOC condition, $F(1,86)=11.32, p=.001$ (Cohen's $d=.08$ ) but not the FTI, $F(1,87)=3.93, p=.051$ (Cohen's $d=.11$; see Table 4). The effect size indicates that $54 \%$ of the BIV scores for the PI participants would be 
expected to fall above the mean score of the AOC (see Figure 3). There were no significant changes when comparing the FTI to AOC, $F(1,83)=1.061, p=.306$ (Cohen's $d=.07$; see Tables $8-9$ ). The FIT and PI led to no other significant changes in measures of body image, eating disturbance, empowerment, or self-esteem.

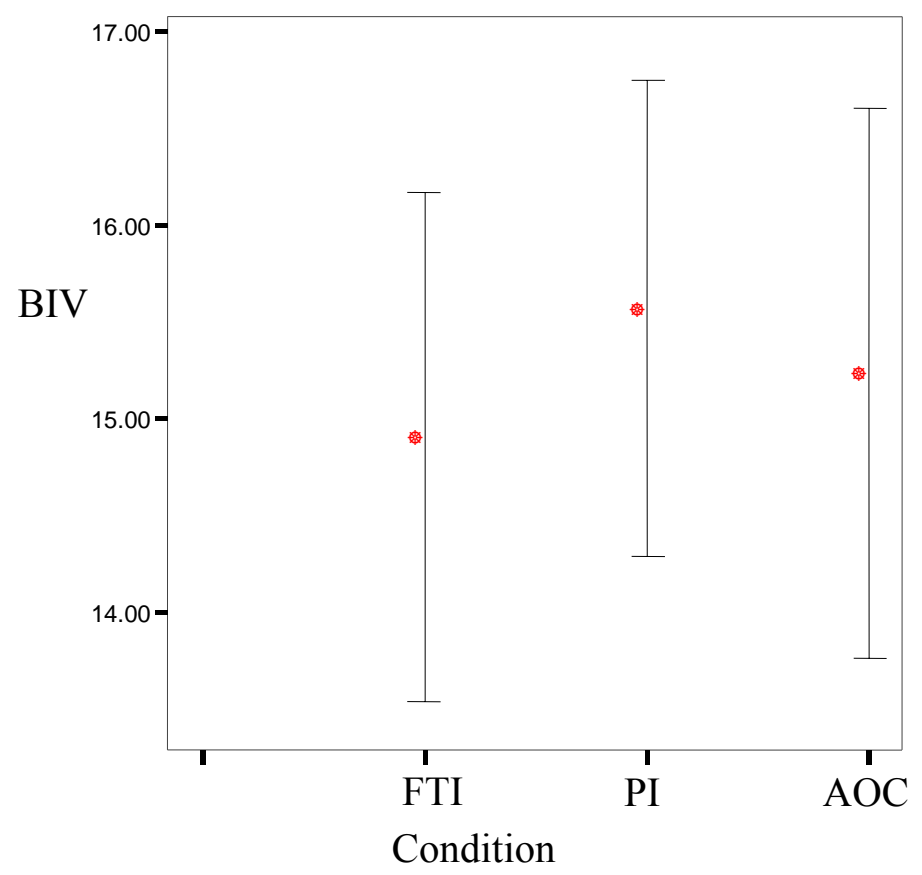

Figure 3: Mean and confidence intervals for body image vulnerability scores by condition. 
Bonferroni-corrected repeated measures MANOVAS were utilized to examine the interactions between Condition and sex role, Condition and level of feminism, and Condition and level of pre-intervention eating disturbance. Only $65 \%$ of participants (i.e., $\mathrm{N}=86$ ) fully completed the BSRI leading to small sample sizes within each condition; therefore, the findings related to sex role must be interpreted with caution (see Table 10). There were no significant Condition by Time by variable (i.e., gender role, level of feminism, or eating disturbance) interactions.

Table 10: Bem sex role by condition

\begin{tabular}{llll}
\hline & Feminine & Masculine & Androgynous \\
\hline FTI & 11 & 1 & 14 \\
PI & 9 & 3 & 18 \\
AOC & 14 & 3 & 13 \\
\hline Total & 34 & 7 & 45 \\
\hline
\end{tabular}




\section{DISCUSSION}

Results indicated that participants who were exposed to a 15-minute feminist theory intervention experienced significant increases in their willingness to self-identify as a feminist and significant improvements in their body image satisfaction when compared with the control group. The effect sizes for change in feminist identification are considered "medium" and indicate participants in the FTI were more likely to increase their self-identification as a feminist when compared with the PI and AOC groups. While there were no changes in standardized measures of feminism, willingness to self-identify may be a more salient reflection of a change towards a feminist schema. Outwardly identifying as a feminist indicates a refusal to be complacent towards the current hegemony of society. Prior to the intervention, participants may have held beliefs in accordance with feminist ideologies but refrained from identifying themselves as feminist for many reasons. For example, believing that feminists are "man-haters" or being concerned about being perceived negatively by others may prevent some women from identifying as feminists, despite their beliefs about equality for women. The FTI may have helped to dispel negative stereotypes, allowing participants to see the connection between their belief systems with those of the feminist movement. Another possibility is that women were unaware of feminist ideologies and either recognized how their current belief system fits with feminism, or their beliefs were changed based on the information presented.

The importance of this particular result relates to the possibilities for change. Increased identification as a feminist may lead women to actively challenge the status quo and work towards the actual definition of feminism, equality for men and women. 
Not only could this shift in schema lead women to challenge existing ideals of beauty, but it also may help buffer some of the well-documented negative effects (e.g., body dissatisfaction) of exposure to unrealistic societal ideals. Although the FTI did not lead to immediate widespread changes in disturbance, the potential shift in schema may lead some women to interpret appearance-related messages differently following the intervention. Since previous research has shown that women who identify as feminists exhibit less body image and eating disturbance than their nonfeminist counterparts (Cash et al., 1997; Dionne et al., 1995; Snyder \& Hasbrouck, 1996), identifying more strongly as a feminist may lead to prevention of or decreases in body image and eating disturbance.

The effect sizes for increases in physical appearance satisfaction, while small, still are meaningful, particularly when compared with the findings of Stice and Shaw (2004; i.e., average body image dissatisfaction effect size of Cohen's $d=.13$ ). The effect sizes indicate that participants in the FTI were more likely to experience an improvement in their physical appearance satisfaction when compared with the PI and AOC groups. Importantly, participants experienced this change without decreases in BMI. Improvements in the FTI group, while significantly better than the AOC, were not significantly better than the PI after Bonferroni corrections; further, the PI did not lead to significant changes over the AOC. The results suggest that components of the FTI were more effective at creating significant positive changes when compared with participants receiving no intervention and may be indicative of the change toward a feminist schema.

It is of interest to note that the experimental effects occurred after only a 15minute intervention. Previous psychoeducational interventions that were long-term (e.g., 
18 lessons), utilized sample sizes of several hundred, and included post intervention discussion groups found no evidence of change in body image disturbance (Irving \& Berel, 2001; Killen et al., 1993; Stice et. al, 2003; Tilgner et al., 2004). Further, the original psychoeducational interventions (e.g., Stormer, 1999) began as small-scale interventions and led to significant decreases in internalization of the thin-ideal and only "trends" towards decreasing body image dissatisfaction. It was not until psychoeducational interventions moved to semester-long college courses that major changes in eating and body image disturbance were found (Stice \& Ragan, 2002). The exposure needed to evoke significant changes using the psychoeducational approach compared with the results of a 15-minute FTI indicate the FTI may be a more efficient and effective means of change.

The PI led to significant improvements in participants' Body Image Vulnerability when compared with the AOC. The PI was designed to serve as a valid intervention comparison for the FTI; therefore, while not predicted, body image improvements due to the PI are not surprising and speak to the legitimacy of its administration. The PI, however, did not lead to significant changes in feminist schema which may be a critical ingredient in reducing body dissatisfaction.

Although the current study addressed several methodological (e.g., random assignment) and statistical (e.g., lack of controlling for initial disturbance levels with repeated measures ANOVAS, excluding effect size estimates) limitations of previous prevention literature (Stice \& Shaw, 2004), it is important to consider the potential reasons why changes in body image and eating disturbance were not more extensive. One issue relates to the familiarity participants already had with the information 
presented. Today's extensive media coverage of topics including eating disorders, plastic surgery, and negative effects of advertising has led to widespread dissemination of much of the information presented in the PI and some of the information in the FTI. In 1989, Glidden and Tracy stated that their psychoeducational intervention may have worked better for traditional women because the sociocultural theory presented was novel information for them, whereas nontraditional women were already aware of social pressures to be thin. Fifteen years later, the information theorized to be novel only to traditional women may now be familiar to both traditional and nontraditional women. This is evidenced by the fact that most participants in both the FTI and PI groups rated the intervention information as "a little new" on a scale that included the options of "None," "A little," "Most," or "All” new. Frequent exposure to the intervention information prior to participation may have diminished its potential experimental effects.

Another possible limitation was that the FTI may have been lacking in focus on personal empowerment and action. Emphasizing personal initiatives is an important aspect of feminist therapy, but much of the FTI focused on feminist theories and related research. Only a short portion of the intervention provided women with ideas about how to take action with their new information (e.g., vote, discontinue buying fashion magazines). Perhaps participants gained a newfound feminist identity, however, they were left feeling unsure of how to proceed. This uncertainty may have been related to unchanged empowerment and disturbance scores. Had the "action" portion been extended, participants may have felt more secure in what role they can play in changing external pressures to be beautiful. 
Another possible explanation for the limited findings is that the credentials of the speaker on the tapes were not disclosed. Based on the social psychology theory of the "sleeper effect," information presented by a source viewed as non-credible still may lead to opinion changes but in a delayed manner (Hovland, Lumsdaine, \& Sheffield, 1949). The post-test assessments were completed immediately after presentation of the information. If, in fact, the participants doubted the information presented due to a lack of established credentials by the presenter, significant and extensive changes in disturbance may not occur immediately after the presentation.

As in all studies, the number of statistical comparisons and possibility of spurious findings must be considered. Multiple comparisons were chosen due to the fact there are so few documented successful intervention studies that it is not only important to explore which interventions may work, but also to ascertain which interventions work for whom. Previously, interventions have resulted in significant changes for specific subpopulations (e.g., traditional or highly disturbed women), thereby limiting the possibility of extensive intervention implementation (Glidden \& Tracey, 1989; Stice et al., 2000). In contrast, the FTI had a more universal impact in that there were no significant interactions between the intervention and other variables. In other words, all participants exposed to the FTI experienced similar changes in feminist schema and physical appearance satisfaction, regardless of sex role, previous feminist identification, or level of eating disturbance. Therefore, the FTI may be a promising approach for reaching the broad spectrum of women subjected to a culture of thinness.

Another limitation to the present study was the relatively small sample size. Much of the body image and eating disturbance literature to date has not reported effect 
sizes, but a recently published meta-analysis of prevention studies reported small effect sizes (i.e., Cohen's $d=.13$ ) for changes in body image disturbance (Stice $\&$ Shaw, 2004). Based on a power analysis using a small effect size (i.e., Cohen's $d=.2$ ) and power of .80 , a total sample size of 966 (i.e., 322 per condition) would have been needed to detect significant changes (Cohen, 2003; Stice \& Shaw, 2004). Another possible explanation for the limited results of this study is that the intervention was brief and did not include active participant involvement. It may be helpful for future interventions to increase the length of a feminist-based intervention and include active participation since interactive prevention programs were found to be more effective at reducing disturbance when compared to didactic programs (Stice \& Shaw, 2004). Adding the "action" component of facilitating a discussion of how women can participate in societal change may foster further feelings of empowerment, increase the success of a feminist intervention, and therefore enhance body image and decrease disordered eating.

In summary, exposure to feminist theory was shown to increase participants' feminist schema and physical appearance satisfaction. This shift in feminist identification holds many possibilities for positive change such as increasing the number of women who are willing to work toward changing society's current ideals of beauty. Further, the increased appearance satisfaction occurred without changes in participants' weight. Even more extensive psychoeducational interventions did not result in positive appearance evaluation changes. In light of previous findings, the potential impact of feminist ideology as an effective intervention component merits continued investigation. Empowering women with information and encouraging active participation in shaping sociocultural standards may not only decrease their personal body image and eating 
disturbance, but also may change the current unrealistic ideals to standards that are healthier and more representative of the average woman. 
APPENDIX A: FEMINIST IDENTITY COMPOSITE 
Please read each of the following items and circle the number that best reflects your agreement with each statement.

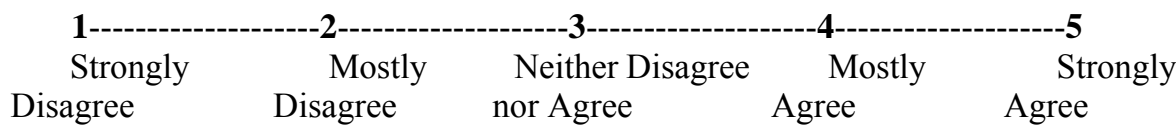

1. I am very committed to a cause that I believe contributes to 1 a more fair and just world for all people.

2. I want to work to improve women's status.

2

3

$4 \quad 5$

3. I am willing to make certain sacrifices to effect change in this society in order to create a nonsexist, peaceful place where all people have equal opportunities.

4. It is very satisfying to me to be able to use my talents and skills in my work in the women's movement.

5. I care very deeply about men and women having equal opportunities in all respects.

6. I choose my "causes" carefully to work for greater equality of all people.

1

2

3

$3-1-2$

45

7. I feel that I am a very powerful and effective spokesperson for the women's issues I am very concerned with right now.

8. On some level, my motivation for almost every activity I engage in is my desire for an egalitarian world.

9. I owe it not only to women but to all people to work for greater opportunity and equality for all.

10. I feel like I have blended my female attributes with my unique personal qualities.

11. I am proud to be competent woman.

12. I have incorporated what is female and feminine into my own unique personality.

13. I enjoy the pride and self-assurance that comes from being a strong female.

14. As I have grown in my beliefs I have realized that it is more important to value women as individuals than as members of a larger group of women.

15. If I were to paint a picture or write a poem, it would probably be about women or women's issues.

$\begin{array}{lllll}1 & 2 & 3 & 4 & 5\end{array}$

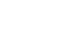

2

3

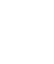

1

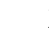

2

4

2

2

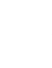

2

2

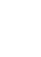

$\begin{array}{lllll}1 & 2 & 3 & 4 & 5 \\ 1 & 2 & 3 & 4 & 5 \\ 1 & 2 & 3 & 4 & 5\end{array}$

2

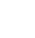

$\begin{array}{llll}2 & 3 & 4 & 5\end{array}$


16. Gradually, I am beginning to see just how sexist society really is.

17. I feel angry when I think about the way I am treated by men and boys.

18. Men receive many advantages in society and because of this are against equality for women.

19. I never realized until recently that I have experienced pression and discrimination as a woman in society.

20. I feel like I've been duped into believing society's perceptions of me as a woman.

$\begin{array}{lllll}1 & 2 & 3 & 4 & 5\end{array}$

21. My female friends are like me in that we are all angry at men and the ways we have been treated as women.

23. In my interactions with men, I am always looking for ways I may be discriminated against because I am female.

24. Regretfully, I can see ways in which I have perpetuated sexist attitudes in the past.

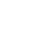

2

$3 \quad 4 \quad 5$

26. I am very interested in women musicians.

$3 \quad 4 \quad 5$

27. I am very interested in women artists.

$3 \quad 4 \quad 5$

28. I am very interested in women's studies.

29. I don't see much point in questioning the general population that men should be more masculine and women should be more feminine.

30. One thing I especially like about being a woman is that men will offer me their seat on a crowded bus or open doors for me because I am a woman.

31. I like being a traditional female.

32. I think that men and women had it better in the 1950's when married women were housewives and their husbands supported them. 
33. If I were married to a man and my husband was offered a job in another state, it would be my obligation to move in support of his career.

34. I think that most women will feel most fulfilled by being a wife and a mother.

35. I think it's lucky that women aren't expected to do some of the more dangerous jobs that men are expected to do,

1

2

$3 \quad 4 \quad 5$

37. I evaluate men as individuals, not as members of a group of oppressors.

2

3

38. I just feel like I need to be around women who share my point of view right now.

$\begin{array}{lllll}1 & 2 & 3 & 4 & 5\end{array}$

39. I feel that some men are sensitive to women's issues.

40. I share most of my social time with a few close women friends who share my feminist values.

2

$3 \quad 4 \quad 5$


APPENDIX B: EMPOWERMENT SCALE 
Please read each of the following items and circle the number that best reflects your agreement with each statement.

$$
\text { 1=Strongly Disagree 2=Disagree 3=Agree 4=Strongly Agree }
$$

\begin{tabular}{|c|c|c|c|c|}
\hline 1. I generally accomplish what I set out to do. & 1 & 2 & 3 & 4 \\
\hline 2. I have a positive attitude about myself. & 1 & 2 & 3 & 4 \\
\hline $\begin{array}{l}\text { 3. When I make plans, I am almost certain to make them } \\
\text { work. }\end{array}$ & 1 & 2 & 3 & 4 \\
\hline 4. I am usually confident about the decisions I make. & 1 & 2 & 3 & 4 \\
\hline 5. I am often able to overcome barriers & 1 & 2 & 3 & 4 \\
\hline $\begin{array}{l}\text { 6. I feel I am a person of worth, at least on an equal basis } \\
\text { with others. }\end{array}$ & 1 & 2 & 3 & 4 \\
\hline 7. I see myself as a capable person. & 1 & 2 & 3 & 4 \\
\hline 8. I am able to do things as well as most other people. & 1 & 2 & 3 & 4 \\
\hline 9. I feel I have a number of good qualities. & 1 & 2 & 3 & 4 \\
\hline 10. I feel powerless most of the time. & 1 & 2 & 3 & 4 \\
\hline 11. Making waves never gets you anywhere. & 1 & 2 & 3 & 4 \\
\hline 12. You can’t fight city hall. & 1 & 2 & 3 & 4 \\
\hline $\begin{array}{l}\text { 13. When I am unsure about something, I usually go along } \\
\text { with the group. }\end{array}$ & 1 & 2 & 3 & 4 \\
\hline $\begin{array}{l}\text { 14. Experts are in the best position to decide what people } \\
\text { should do or learn }\end{array}$ & 1 & 2 & 3 & 4 \\
\hline
\end{tabular}




\begin{tabular}{|c|c|c|c|c|}
\hline 15. Most of the misfortunes in my life were due to bad luck. & 1 & 2 & 3 & 4 \\
\hline 16. Usually, I feel alone. & 1 & 2 & 3 & 4 \\
\hline $\begin{array}{l}\text { 17. People have no right to get angry just because they } \\
\text { don't like something. }\end{array}$ & 1 & 2 & 3 & 4 \\
\hline $\begin{array}{l}\text { 18. People have a right to make their own decisions, even if } \\
\text { they are bad ones. }\end{array}$ & 1 & 2 & 3 & 4 \\
\hline $\begin{array}{l}\text { 19. People should try to live their lives the way they want } \\
\text { to. }\end{array}$ & 1 & 2 & 3 & 4 \\
\hline $\begin{array}{l}\text { 20. People working together can have } \\
\text { an effect on their community. }\end{array}$ & 1 & 2 & 3 & 4 \\
\hline $\begin{array}{l}\text { 21. People have more power if they join together as a } \\
\text { group. }\end{array}$ & 1 & 2 & 3 & 4 \\
\hline $\begin{array}{l}\text { 22. Working with others in my community can help to } \\
\text { change things for the better. }\end{array}$ & 1 & 2 & 3 & 4 \\
\hline 23. Very often a problem can be solved by taking action. & 1 & 2 & 3 & 4 \\
\hline 24. People are limited only by what they think possible. & 1 & 2 & 3 & 4 \\
\hline $\begin{array}{l}\text { 25. I can pretty much determine what will happen in my } \\
\text { life. }\end{array}$ & 1 & 2 & 3 & 4 \\
\hline 26. I am generally optimistic about the future. & 1 & 2 & 3 & 4 \\
\hline 27. Very often a problem can be solved by taking action. & 1 & 2 & 3 & 4 \\
\hline $\begin{array}{l}\text { 28. Getting angry about something is often the first step } \\
\text { toward changing it. }\end{array}$ & 1 & 2 & 3 & 4 \\
\hline
\end{tabular}




\begin{tabular}{|l|c|c|c|c|}
\hline $\begin{array}{l}\text { 29. People have no right to get angry just because they } \\
\text { don't like something. }\end{array}$ & 1 & 2 & 3 & 4 \\
\hline 30. Getting angry about something never helps. & 1 & 2 & 3 & 4 \\
\hline 31. Making waves never gets you anywhere. & 1 & 2 & 3 & 4 \\
\hline
\end{tabular}


APPENDIX C: BEM SEX ROLE INVENTORY 
Please indicate on the 7-point scale how well each of the sixty attributes listed below describes you $(1=$ I seldom exhibit this attribute, and $7=$ almost always exhibit this attribute).

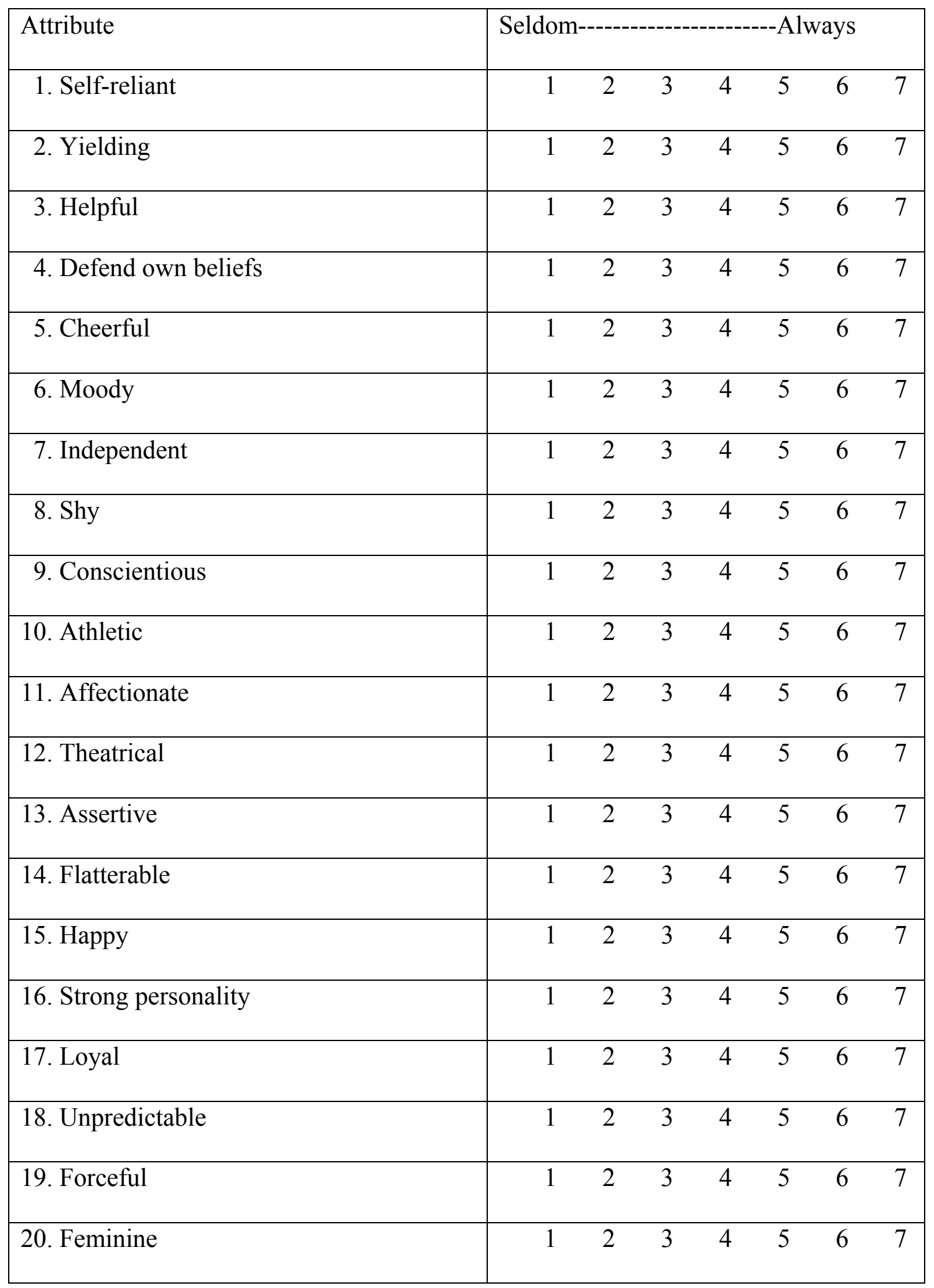




\begin{tabular}{|c|c|c|c|c|c|c|c|}
\hline 21. Reliable & 1 & 2 & 3 & 4 & 5 & 6 & 7 \\
\hline 22. Analytical & 1 & 2 & 3 & 4 & 3 & $\mathrm{c}$ & 7 \\
\hline 23. Sympathetic & 1 & 2 & 3 & 4 & 5 & ( & 7 \\
\hline 24. Jealous & 1 & 2 & 3 & 4 & 5 & 6 & 7 \\
\hline 25. Has leadership abilities & 1 & 2 & 3 & 4 & 5 & ( & 7 \\
\hline 26. Sensitive to the needs of others & 1 & 2 & 3 & 4 & 5 & ( & 7 \\
\hline 27. Truthful & 1 & 2 & 3 & 4 & 5 & ( & 7 \\
\hline 28. Willing to take risks & 1 & 2 & 3 & 4 & 5 & ( & 7 \\
\hline 29. Understanding & 1 & 2 & 3 & 4 & 5 & ( & 7 \\
\hline 30. Secretive & 1 & 2 & 3 & 4 & 5 & ( & 7 \\
\hline 31. Makes decisions easily & 1 & 2 & 3 & 4 & 5 & ( & 7 \\
\hline 32. Compassionate & 1 & 2 & 3 & 4 & 5 & ( & 7 \\
\hline 33. Sincere & 1 & 2 & 3 & 4 & 5 & 7 & 7 \\
\hline 34. Self-sufficient & 1 & 2 & 3 & 4 & 5 & ( & 7 \\
\hline 35. Eager to soothe hurt feelings & 1 & 2 & 3 & 4 & 5 & ( & 7 \\
\hline 36. Conceited & 1 & 2 & 3 & 4 & 5 & ( & 7 \\
\hline 37. Dominant & 1 & 2 & 3 & 4 & 3 & ( & 7 \\
\hline 38. Soft spoken & 1 & 2 & 3 & 4 & & ( & 7 \\
\hline 39. Likable & 1 & 2 & 3 & 4 & & 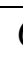 & 7 \\
\hline 40. Masculine & 1 & 2 & 3 & 4 & & ( & 7 \\
\hline 41. Warm & 1 & 2 & 3 & 4 & & ( & 7 \\
\hline 42. Solemn & 1 & 2 & 3 & 4 & & ( & 7 \\
\hline 43. Willing to take a stand & 1 & 2 & 3 & 4 & 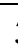 & ( & 7 \\
\hline
\end{tabular}




\begin{tabular}{|c|c|c|c|c|c|c|c|}
\hline 44. Tender & 1 & 2 & 3 & 4 & 5 & 6 & 7 \\
\hline 45. Friendly & 1 & 2 & 3 & 4 & 5 & 6 & 7 \\
\hline 46. Aggressive & 1 & 2 & 3 & 4 & 5 & 6 & 7 \\
\hline 47. Gullible & 1 & 2 & 3 & 4 & 5 & 6 & 7 \\
\hline 48. Inefficient & 1 & 2 & 3 & 4 & 5 & 6 & 7 \\
\hline 49. Acts as a leader & 1 & 2 & 3 & 4 & 5 & 6 & 7 \\
\hline 50. Childlike & 1 & 2 & 3 & 4 & 5 & 6 & 7 \\
\hline 51. Adaptable & 1 & 2 & 3 & 4 & 5 & 6 & 7 \\
\hline 52. Individualistic & 1 & 2 & 3 & 4 & 5 & 6 & 7 \\
\hline 53. Does not use harsh language & 1 & 2 & 3 & 4 & 5 & 6 & 7 \\
\hline 54. Unsystematic & 1 & 2 & 3 & 4 & 5 & 6 & 7 \\
\hline 55. Competitive & 1 & 2 & 3 & 4 & 5 & 6 & 7 \\
\hline 56. Loves children & 1 & 2 & 3 & 4 & 5 & 6 & 7 \\
\hline 57. Tactful & 1 & 2 & 3 & 4 & 5 & 6 & 7 \\
\hline 58. Ambitious & 1 & 2 & 3 & 4 & 5 & 6 & 7 \\
\hline 59. Gentle & 1 & 2 & 3 & 4 & 5 & 6 & 7 \\
\hline 60. Conventional & 1 & 2 & 3 & 4 & 5 & 6 & 7 \\
\hline
\end{tabular}




\section{APPENDIX D: SOCIOCULTURAL ATTITUDES TOWARD APPEARANCE QUESTIONNAIRE}




\section{SATAQ}

Please read each of the following items and circle the number that best reflects your agreement with the statement.

\begin{tabular}{|c|c|c|}
\hline \multicolumn{3}{|c|}{ 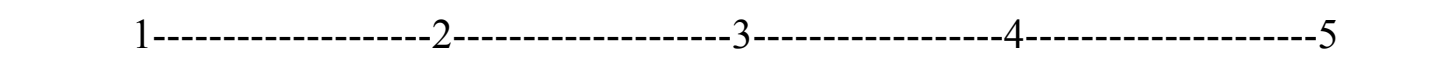 } \\
\hline & Neither agree & CompI \\
\hline Disagree & nor disagree & Agree \\
\hline
\end{tabular}

1. Women who appear in TV shows and movies project the type of appearance that I see as my goal.

$\begin{array}{lllll}1 & 2 & 3 & 4 & 5\end{array}$

2. I believe clothes look better on thin models.

$\begin{array}{lllll}1 & 2 & 3 & 4 & 5\end{array}$

3. Music videos that show thin women make me wish that I were thin.
1
2
3
4
5

4. I do not wish to look like the models in the magazines.

$\begin{array}{lllll}1 & 2 & 3 & 4 & 5\end{array}$

5. I tend to compare my body to people in magazines and on TV.

$\begin{array}{lllll}1 & 2 & 3 & 4 & 5\end{array}$

6. In our society, fat people are not regarded as unattractive.
1
2
3
4
5

7. Photographs of thin women make me wish that I were thin.
1
2
3
4
5

8. Attractiveness is very important if you want to get ahead in our culture.
1
2
3
4
5

9. It is important for people to work hard on their figures/physiques if they want to succeed in today's culture.

$\begin{array}{lllll}1 & 2 & 3 & 4 & 5\end{array}$

10. Most people do not believe that the thinner you are, the better you look in clothes.
1
2
3
4
5

11. People think the thinner you are, the better you look in clothes.

1

2

3

4 


\section{APPENDIX E: MULTIDIMENSIONAL BODY SELF-RELATIONS QUESTIONNAIRE}




\section{PART I:}

Please read each statement and CIRCLE the number that best indicates the extent to which you agree or disagree with each statement.

$$
\begin{array}{ccccc}
1=\text { DEFINITELY } & 2=\text { MOSTLY } & 3=\text { NEITHER } & 4=\text { MOSTLY } & 5=\text { DEFINITELY } \\
\text { AGREE } & \text { AGREE } & \text { DISAGREE NOR AGREE } & \text { AGREE } & \text { AGREE }
\end{array}
$$

\begin{tabular}{lllllll} 
1. & My body is sexually appealing. & $\mathbf{1}$ & $\mathbf{2}$ & $\mathbf{3}$ & $\mathbf{4}$ & $\mathbf{5}$ \\
\hline 2. & I like my looks just the way they are. & $\mathbf{1}$ & $\mathbf{2}$ & $\mathbf{3}$ & $\mathbf{4}$ & $\mathbf{5}$ \\
\hline 3. & Most people would consider me good-looking. & $\mathbf{1}$ & $\mathbf{2}$ & $\mathbf{3}$ & $\mathbf{4}$ & $\mathbf{5}$ \\
\hline 4. & I like the way I look without my clothes. & $\mathbf{1}$ & $\mathbf{2}$ & $\mathbf{3}$ & $\mathbf{4}$ & $\mathbf{5}$ \\
\hline 5. & I like the way my clothes fit me. & $\mathbf{1}$ & $\mathbf{2}$ & $\mathbf{3}$ & $\mathbf{4}$ & $\mathbf{5}$ \\
\hline 6. & I dislike my physique. & $\mathbf{1}$ & $\mathbf{2}$ & $\mathbf{3}$ & $\mathbf{4}$ & $\mathbf{5}$ \\
\hline 7. & I am physically attractive. & $\mathbf{1}$ & $\mathbf{2}$ & $\mathbf{3}$ & $\mathbf{4}$ & $\mathbf{5}$ \\
\hline
\end{tabular}

\section{PART II:}

Please read each statement and CIRCLE the letter that best indicates the extent to which you are satisfied or dissatisfied with various parts of your body.

$$
\begin{array}{lcccc}
1=\mathrm{VERY} & 2=\text { MOSTLY } & 3=\text { NEITHER SATISFIED } & 4=\text { MOSTLY } & 5=\text { VERY } \\
\text { DISSATISFIED } & \text { DISSATISFIED } & \text { NOR DISSATISFIED } & \text { SATISFIED } & \text { SATISFIED }
\end{array}
$$

\begin{tabular}{lllllll} 
8. & Face (facial features, complexion) & $\mathbf{1}$ & $\mathbf{2}$ & $\mathbf{3}$ & $\mathbf{4}$ & $\mathbf{5}$ \\
\hline 9. & Hair (color, thickness, texture) & $\mathbf{1}$ & $\mathbf{2}$ & $\mathbf{3}$ & $\mathbf{4}$ & $\mathbf{5}$ \\
\hline 10. & Lower torso (buttocks, hips, thighs, legs, etc.) & $\mathbf{1}$ & $\mathbf{2}$ & $\mathbf{3}$ & $\mathbf{4}$ & $\mathbf{5}$ \\
\hline 11. & Mid torso (waist, stomach) & $\mathbf{1}$ & $\mathbf{2}$ & $\mathbf{3}$ & $\mathbf{4}$ & $\mathbf{5}$ \\
\hline 12. & Upper torso (chest or breasts, shoulders, arms) & $\mathbf{1}$ & $\mathbf{2}$ & $\mathbf{3}$ & $\mathbf{4}$ & $\mathbf{5}$ \\
\hline 13. & Muscle tone & $\mathbf{1}$ & $\mathbf{2}$ & $\mathbf{3}$ & $\mathbf{4}$ & $\mathbf{5}$ \\
\hline 14. & Weight & $\mathbf{1}$ & $\mathbf{2}$ & $\mathbf{3}$ & $\mathbf{4}$ & $\mathbf{5}$ \\
\hline 15. & Height & $\mathbf{1}$ & $\mathbf{2}$ & $\mathbf{3}$ & $\mathbf{4}$ & $\mathbf{5}$ \\
\hline 16. & Overall appearance & $\mathbf{1}$ & $\mathbf{2}$ & $\mathbf{3}$ & $\mathbf{4}$ & $\mathbf{5}$ \\
\hline
\end{tabular}


APPENDIX F: PHYSICAL APPEARANCE STATE AND TRAIT ANXIETY SCALE 


\section{PASTAS}

The statements listed below are to be used to describe how often IN GENERAL (that is, usually), you feel anxious, tense, or nervous about your body or specific parts of your body. Please read each statement and CIRCLE the number that best indicates the extent to which each statement holds true IN GENERAL. Remember, there are no right or wrong answers.

0 = NEVER $1=$ RARELY $2=$ SOMETIMES $3=$ OFTEN $4=$ ALMOST ALWAYS

IN GENERAL, I feel anxious, tense, concerned, or nervous about:

\begin{tabular}{llccccc}
\hline & & Never & Rarely & Sometimes & Often & Always \\
1. & the extent to which I look overweight. & $\mathbf{0}$ & $\mathbf{1}$ & $\mathbf{2}$ & $\mathbf{3}$ & $\mathbf{4}$ \\
\hline 2. & my thighs. & $\mathbf{0}$ & $\mathbf{1}$ & $\mathbf{2}$ & $\mathbf{3}$ & $\mathbf{4}$ \\
\hline 3. & my buttocks. & $\mathbf{0}$ & $\mathbf{1}$ & $\mathbf{2}$ & $\mathbf{3}$ & $\mathbf{4}$ \\
\hline 4. & my hips. & $\mathbf{0}$ & $\mathbf{1}$ & $\mathbf{2}$ & $\mathbf{3}$ & $\mathbf{4}$ \\
\hline 5. & my stomach (abdomen). & $\mathbf{0}$ & $\mathbf{1}$ & $\mathbf{2}$ & $\mathbf{3}$ & $\mathbf{4}$ \\
\hline 6. & my legs. & $\mathbf{0}$ & $\mathbf{1}$ & $\mathbf{2}$ & $\mathbf{3}$ & $\mathbf{4}$ \\
\hline 7. & my waist. & $\mathbf{0}$ & $\mathbf{1}$ & $\mathbf{2}$ & $\mathbf{3}$ & $\mathbf{4}$ \\
\hline 8. & my muscle tone. & $\mathbf{0}$ & $\mathbf{1}$ & $\mathbf{2}$ & $\mathbf{3}$ & $\mathbf{4}$ \\
\hline 9. & my ears. & $\mathbf{0}$ & $\mathbf{1}$ & $\mathbf{2}$ & $\mathbf{3}$ & $\mathbf{4}$ \\
\hline 10. & my lips. & $\mathbf{0}$ & $\mathbf{1}$ & $\mathbf{2}$ & $\mathbf{3}$ & $\mathbf{4}$ \\
\hline 11. & my wrists. & $\mathbf{0}$ & $\mathbf{1}$ & $\mathbf{2}$ & $\mathbf{3}$ & $\mathbf{4}$ \\
\hline 12. & my hands. & $\mathbf{0}$ & $\mathbf{1}$ & $\mathbf{2}$ & $\mathbf{3}$ & $\mathbf{4}$ \\
\hline 13. & my forehead. & $\mathbf{0}$ & $\mathbf{1}$ & $\mathbf{2}$ & $\mathbf{3}$ & $\mathbf{4}$ \\
\hline 14. & my neck. & $\mathbf{0}$ & $\mathbf{1}$ & $\mathbf{2}$ & $\mathbf{3}$ & $\mathbf{4}$ \\
\hline 15. & my chin. & $\mathbf{0}$ & $\mathbf{1}$ & $\mathbf{2}$ & $\mathbf{3}$ & $\mathbf{4}$ \\
\hline 16. & my feet. & $\mathbf{0}$ & $\mathbf{1}$ & $\mathbf{2}$ & $\mathbf{3}$ & $\mathbf{4}$ \\
\hline & & & & \\
\hline
\end{tabular}


APPENDIX G: APPEARANCE SCHEMA INVENTORY 


\section{$A S I$}

Indicate your beliefs about these items using the 1 to 5 scale below.

\begin{tabular}{|c|c|c|c|c|}
\hline $1=\begin{array}{r}\text { Strongly } \\
\text { Disagree }\end{array}$ & $2=\underset{\text { Disagree }}{\text { Mostly }}$ & $\begin{aligned} 3= & \text { Neither } \\
& \text { Disagree nor } \\
& \text { Agree }\end{aligned}$ & $\begin{array}{c}4=\text { Mostly } \\
\text { Agree }\end{array}$ & $\begin{array}{c}5=\text { Strongly } \\
\text { Agree }\end{array}$ \\
\hline
\end{tabular}

\begin{tabular}{|c|c|c|c|c|c|}
\hline 1. What I look like is an important part of who I am. & 1 & 2 & 3 & 4 & 5 \\
\hline $\begin{array}{l}\text { 2. What's wrong with my appearance is one of the first } \\
\text { things that people will notice about me. }\end{array}$ & 1 & 2 & 3 & 4 & 5 \\
\hline $\begin{array}{l}\text { 3. One's outward physical appearance is a sign of the } \\
\text { character of the inner person }\end{array}$ & 1 & 2 & 3 & 4 & 5 \\
\hline $\begin{array}{l}\text { 4. If I could look just as I wish, my life would be much } \\
\text { happier. }\end{array}$ & 1 & 2 & 3 & 4 & 5 \\
\hline $\begin{array}{l}\text { 5. If people know how I really look, they would like } \\
\text { me less. }\end{array}$ & 1 & 2 & 3 & 4 & 5 \\
\hline $\begin{array}{l}\text { 6. By controlling my appearance, I can control many } \\
\text { of the social and emotional events in my life. }\end{array}$ & 1 & 2 & 3 & 4 & 5 \\
\hline $\begin{array}{l}\text { 7. My appearance is responsible for much of what has } \\
\text { happened to me in my life. }\end{array}$ & 1 & 2 & 3 & 4 & 5 \\
\hline 8. I should do whatever I can to always look my best. & 1 & 2 & 3 & 4 & 5 \\
\hline 9. Aging will make me less attractive. & 1 & 2 & 3 & 4 & 5 \\
\hline $\begin{array}{l}\text { 10. For women: To be feminine, a woman must be as } \\
\text { pretty as possible. }\end{array}$ & 1 & 2 & 3 & 4 & 5 \\
\hline $\begin{array}{l}\text { For men: To be masculine, a man must be as } \\
\text { handsome as possible. }\end{array}$ & & & & & \\
\hline $\begin{array}{l}\text { 11. The media's messages in our society make it } \\
\text { impossible for me to be satisfied with my appearance. }\end{array}$ & 1 & 2 & 3 & 4 & 5 \\
\hline $\begin{array}{l}\text { 12. The only way I could ever like my looks would be } \\
\text { to change what I look like. }\end{array}$ & 1 & 2 & 3 & 4 & 5 \\
\hline 13. Attractive people have it all. & 1 & 2 & 3 & 4 & 5 \\
\hline
\end{tabular}


APPENDIX H: THE SELF-ESTEEM INVENTORY 
BELOW IS A LIST OF STATEMENTS DEALING WITH YOUR GENERAL

FEELINGS ABOUT YOURSELF. IF YOU STRONGLY AGREE, CIRCLE SA. IF

YOU AGREE WITH THE STATEMENT, CIRCLE $\underline{\mathbf{A}}$. IF YOU DISAGREE, CIRCLE

D. IF YOU STRONGLY DISAGREE, CIRCLE SD.

\begin{tabular}{|l|l|l|l|l|}
\hline & $\begin{array}{l}\mathbf{1} \\
\text { Strongly } \\
\text { Agree }\end{array}$ & $\begin{array}{l}\mathbf{2} \\
\text { Agree }\end{array}$ & $\begin{array}{l}\mathbf{3} \\
\text { Disagree }\end{array}$ & $\begin{array}{l}\mathbf{4} \\
\text { Strongly } \\
\text { Disagree }\end{array}$ \\
\hline $\begin{array}{l}\text { 1. I feel that I am a person of worth, at least } \\
\text { on an equal plane with others. }\end{array}$ & SA & A & D & SD \\
\hline $\begin{array}{l}\text { 2. I feel that I have a number of good } \\
\text { qualities. }\end{array}$ & SA & A & D & SD \\
\hline $\begin{array}{l}\text { 3. All in all, I am inclined to feel that I am a } \\
\text { failure. }\end{array}$ & SA & A & D & SD \\
\hline $\begin{array}{l}\text { 4. I am able to do things as well as most other } \\
\text { people. }\end{array}$ & SA & A & D & SD \\
\hline 5. I feel I do not have much to be proud of. & SA & A & D & SD \\
\hline 6. I take a positive attitude toward myself. & SA & A & D & SD \\
\hline 7. On the whole, I am satisfied with myself. & SA & A & D & SD \\
\hline $\begin{array}{l}\text { 8. I wish I could have more respect for } \\
\text { myself. }\end{array}$ & SA & A & D & SD \\
\hline 9. I certainly feel useless at times. & SA & A & D & SD \\
\hline 10. At times I think I am no good at all. & SA & A & D & SD \\
\hline
\end{tabular}


APPENDIX I: EATING DISORDERS INVENTORY-II 
Please read each statement and CIRCLE the number that best indicates how often you agree with the following statements:

$1=$ NEVER

2 = RARELY

$3=$ SOMETIMES

$4=$ OFTEN

5 = USUALLY

$6=$ ALWAYS

\begin{tabular}{llllllll} 
1. & I think my stomach is too big. & $\mathbf{1}$ & $\mathbf{2}$ & $\mathbf{3}$ & $\mathbf{4}$ & $\mathbf{5}$ & $\mathbf{6}$ \\
\hline $\begin{array}{l}\text { 2. } \\
\text { 3. I think that my thighs are too large. }\end{array}$ & $\mathbf{1}$ & $\mathbf{2}$ & $\mathbf{3}$ & $\mathbf{4}$ & $\mathbf{5}$ & $\mathbf{6}$ \\
\hline $\begin{array}{l}\text { 4. } \\
\text { I feel satisfied with the shape of my } \\
\text { body. }\end{array}$ & $\mathbf{1}$ & $\mathbf{2}$ & $\mathbf{3}$ & $\mathbf{4}$ & $\mathbf{5}$ & $\mathbf{6}$ \\
\hline 5. & I like the shape of my buttocks. & $\mathbf{1}$ & $\mathbf{2}$ & $\mathbf{3}$ & $\mathbf{4}$ & $\mathbf{5}$ & $\mathbf{6}$ \\
\hline 6. & I think my hips are too big. & $\mathbf{1}$ & $\mathbf{2}$ & $\mathbf{3}$ & $\mathbf{4}$ & $\mathbf{5}$ & $\mathbf{6}$ \\
\hline $\begin{array}{l}\text { 7. } \\
\text { I think that my thighs are just the right }\end{array}$ & $\mathbf{1}$ & $\mathbf{2}$ & $\mathbf{3}$ & $\mathbf{4}$ & $\mathbf{5}$ & $\mathbf{6}$ \\
8ize. & I think my buttocks are too large. & $\mathbf{1}$ & $\mathbf{2}$ & $\mathbf{3}$ & $\mathbf{4}$ & $\mathbf{5}$ & $\mathbf{6}$ \\
\hline 9. & I think my hips are just the right size. & $\mathbf{1}$ & $\mathbf{2}$ & $\mathbf{3}$ & $\mathbf{4}$ & $\mathbf{5}$ & $\mathbf{6}$ \\
\hline
\end{tabular}


APPENDIX J: VISUAL ANALOGUE SCALES 


\section{VAS}

The items listed below are used to describe how you feel right now. Use the following scale by drawing a vertical slash ( ) through the line to indicate the degree to which you feel right now about what is asked:

\section{Satisfaction with my physical appearance}

Not at all satisfied

Completely satisfied

\section{Investment in my physical appearance}

Not at all invested

Completely invested

\section{Importance of my physical appearance}

Not at all important

Completely important

4. Anxiety about my physical appearance

Not at all anxious

Completely anxious

5. The degree to which my life satisfaction is based on my physical appearance

Not at all based

Completely based

\section{Sexual appeal of my physical appearance}

Not at all appealing

Completely appealing 
APPENDIX K: CONTOUR DRAWING RATING SCALE 


\section{CDRS}
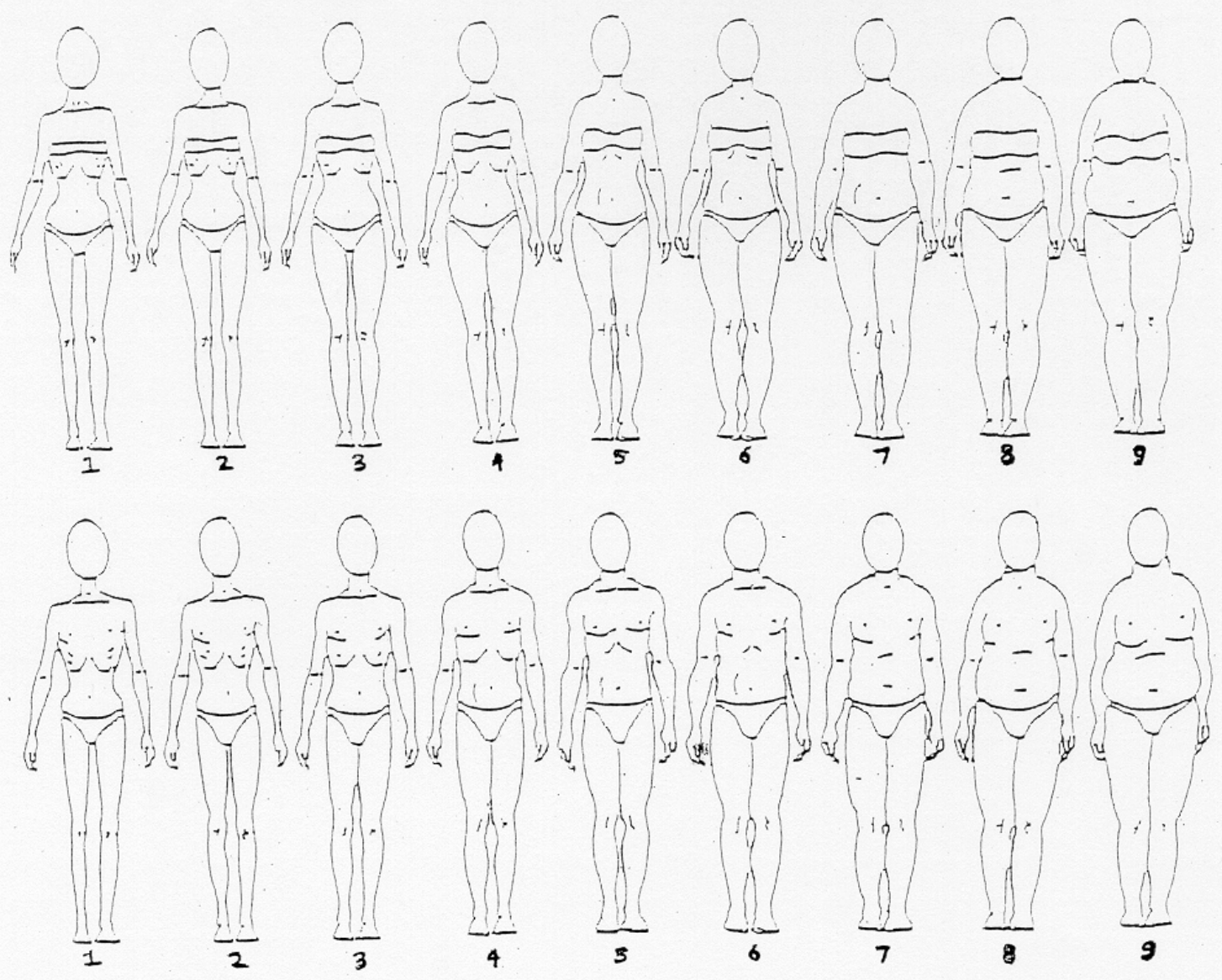

1. Choose your ideal male figure

2. Choose your ideal female figure

3. Choose the female figure that you think men find the most attractive

Now choose the range of opposite-sex figures which you would find acceptable for a potential romantic partner.

4. Smallest acceptable figure I would consider dating 5. Largest acceptable figure I would consider dating 
APPENDIX L: EATING ATTITUDES TEST 
Please indicate on the line at the left the answer which applies best to each of the numbered statements. All of the results will be strictly confidential. Most of the questions directly relate to food or eating, although other types of questions have been included. Please answer each question carefully. Thank you.

$$
\begin{array}{ll}
0=\text { Never } & 3=\text { Often } \\
1=\text { Rarely } & 4=\text { Very Often } \\
2=\text { Sometimes } & 5=\text { Always }
\end{array}
$$

1. Like eating with other people.

2. Prepare foods for others but do not eat what I cook.

3. Become anxious prior to eating.

4. Am terrified of being overweight.

5. Avoid eating when I am hungry.

6. Find myself preoccupied with food.

7. Have gone on eating binges where I feel that I may not be able to stop.

8. Cut my food into small pieces.

9. Aware of the calorie content of foods that I eat.

10. Particularly avoid foods with a high carbohydrate content (eg, bread, potatoes, rice, etc.).

11. Feel bloated after meals.

12. Feel that others would prefer if I ate more.

13. Vomit after I have eaten.

14. Feel extremely guilty after eating.

15. Am preoccupied with a desire to be thinner.

16. Exercise strenuously to burn off calories.

17. Weigh myself several times a day.

18. Like my clothes to fit tightly.

19. Enjoy eating meat.

20. Wake up early in the morning.

21. Eat the same foods day after day.

22. Think about burning my calories when I exercise.

23. Have regular menstrual periods.

24. Other people think that I am too thin.

25. Am preoccupied with the thought of having fat on my body.

26. Take longer than others to eat my meals.

27. Enjoy eating at restaurants.

28. Take laxatives.

29. Avoid foods with sugar in them.

30. Eat diet foods.

31. Feel that food controls my life.

32. Display self control around food.

33. Feel that others pressure me to eat.

34. Give too much time and thought to food.

35. Suffer from constipation.

36. Feel uncomfortable after eating sweets.

37. Engage in dieting behavior.

38. Like my stomach empty.

39. Enjoy trying new rich foods.

40. Have the impulse to vomit after meals. 


\section{APPENDIX M: FEMINIST THEORY INTERVENTION}

\section{TRANSCRIPT}


There is a disease spreading. It taps on the shoulder of America's firstborn sons, its best and brightest. At its touch, they turn away from food. Their bones well out from receding flesh. First tens, then hundreds, then thousands, until, among the most affluent families, one young son in five is stricken. Many are hospitalized, many die.

These boys are the golden ones to whom the reins of the world are to be lightly tossed: the captain of the Princeton football team, the head of the Berkley debating club.

They have grown thin and still more thin. They lose their libido, and can no longer make the effort to joke or argue. There is no medical reason.

The disease mutates again. It becomes apparent that for every well-born living skeleton there are at least three other young men, also bright lights, who do something just as strange. (Please turn to page 2) Once they have swallowed their steaks and wine, they hide away, to thrust their fingers down their throats and spew out all the nourishment in them. They arrange their lives so they can spend hours each day hunched over like that, their highly trained minds telescoped around two shameful holes: mouth, toilet; toilet, mouth.

Meanwhile, people are waiting for them to take up their places: assistantships at the New York Times, seats on the stock exchange. What is happening to the fine young men? It hurts to look at them. (Please turn to page 3 )

This excerpt from Naomi Wolf's dramatic essay illustrates the dire situation of eating and body image disturbance among women today and how the gender of the afflicted can influence society's reaction to the crisis. If men really were afflicted by eating disorders, how would society react? With funding, research, and mandates? The reality is that we are losing people to these diseases -- we are losing girls and women. Ninety to ninety-five percent of people suffering from an eating disorder are females.

Sex discrimination in health research has existed throughout the centuries.

Historically, health researchers studied diseases in men and then applied their findings to women. (Please turn to page 4) It was not until the late 1980s that the National Institute of Health began insisting that women be included in health research. Alarmingly, the number of individuals with anorexia who will die is approximately 12 times higher than 
the annual mortality due to all causes of death among females ages 15 to 24 . Some of the "best and brightest" females are being lost to self-starvation.

The problem does not just exist for those diagnosed with an eating disorder. Average, everyday women report serious body image disturbance and risky dieting behaviors. In 1995, over $60 \%$ of women sampled reported being unsatisfied with their current weight, muscle tone, and mid and lower torso. Sadly, girls as young as 5 years old report dieting and believe they are "fat." (Please turn to page 5) Who will fight on our behalf? What, if anything, will be done to stop the epidemic proportions of females who hate their bodies?

Feminists have long fought for equal rights for women. Historically, battles have focused on the right to be educated, to own property, to vote, to be included in medical research, and so on. Feminism and the women's movement resulted in many of the opportunities and equalities that so many of us take for granted today. But, for many people, the terms "feminism" and "feminist" conjure up ideas of angry, unshaven manhaters. (Please turn to page 6) Many individuals don't really understand what feminism is. Well, contrary to any stereotypes, feminism is defined as a belief in the social, political, and economic equality of the sexes. Using that definition, many of us may be more feminist than we ever realized.

Recently, feminists' attention has been drawn to the battle to preserve women's minds and bodies, as rates of body image and eating disturbance grow at an alarming pace. In understanding this battle, we must first ask, "Why do body image and eating disorders affect so many more women than men?" The answer may relate to the vastly different socialization of the genders. (Please turn to page 7) Traditionally, western 
cultures have believed in a division between the mind and the body: men have been viewed as the mind and therefore the logic, whereas women have been viewed as the body, or the object. This division has resulted in the objectification of women's bodies throughout history. Subsequently, men typically have been evaluated on their career and monetary success, and women more often are judged on their physical appearance. As a result of all of this emphasis and value placed on women's attractiveness, women's self worth often is dependent on their physical appearance, leading to a great deal of energy, both mental and physical, spent on altering their appearance to look more attractive. (Please turn to page 8 )

Women spend countless hours and billions of dollars every year to prune, pluck, shape, and shave their bodies. Some feminists view this obsession as a form of subversive sexism. Women's focus has become centered on their bodies that they view as fat and inadequate. As a result, some girls and women become apathetic -- they don't feed their bodies and minds. Rather than fight to challenge the destructive emphasis on their appearance, women sometimes find themselves sucked into the pursuit of staying beautiful and defying their age with the dozens of face creams, cosmetic surgery procedures, diets, and exercise programs marketed to them every time they turn on the tv or open a magazine. (Please turn to page 9)

Feminists, however, are trying to fight this battle that afflicts us, our mothers, our sisters, and our friends. Many of the current theories view eating disorders as diseases that affect individuals, but feminists view disturbance as the logical result of a society obsessed with appearance and thinness. It is not women who are disturbed, but society. Feminist researchers have developed three theories to explain disturbance, and all of 
them focus on disturbance as a natural consequence of external pressures to be unrealistically thin.

One feminist theory of body image disturbance, Culture of Thinness, concentrates on society's obsession with thinness. This obsession suppresses women by setting forth unrealistic physical standards that are made to appear attainable. (Please turn to page 10) Unable to achieve this standard, women may develop body image and eating disturbance. In fact, researchers have found that frequently reading fashion magazines is related to greater body image dissatisfaction, investment in being thin, use of more weight management techniques, and more eating disturbance.

Historically, curvy, voluptuous women were the epitome of attractiveness and sexuality. This shapely ideal was visible in art, such as Botticelli's Venus and Degas's Bather. Women's round, ample hips and breasts were not hidden behind loose clothing, but glorified as the signature of beauty. The curvaceous ideal was documented as recently as the Victorian age, when women fondly referred to fat as their "silken layer." (Please turn to page 11)

For centuries women have attempted to alter their appearance to fit within societal standards. Previous standards of curvaceousness were a more natural and attainable shape for women. Recently, the ideal shape has become thin and angular. The current ideal can be traced back to Twiggy, a popular model of the 1960s who was 5' 7" and weighed 98 pounds, well below her healthy weight range. The heroin chic of the 1990s with models such as Kate Moss also exemplified the ultra-thin ideal. The super-slender physiques on the runways and in magazines have been described as gawky, bare-boned, and adolescent. Current ideals are devoid of the secondary sex characteristics of women 
(like breasts and hips) and represent a shape that only 5 to $10 \%$ of women possess naturally. (Please turn to page 12) Ninety to ninety-five percent of women are left striving dangerously for a shape they could never obtain, even with proper diet and exercise. The current weights of Playboy models and Miss America contestants are, on average, 13 to $19 \%$ below a healthy recommended weight for their height. This is alarming since one major symptom of anorexia nervosa is a body weight $15 \%$ below recommended standards. Women are spending an astronomical amount of time and money on dieting, and feeling hungry has become part of life for many.

A second feminist theory of body image disturbance, Weight as Power and Control, asserts that, historically, women have had a lack of control over their lives, with limited access to education, government, choice of spouse, or independently owning possessions. (Please turn to page 13) In response to this, women began to focus on their physical appearance and controlling their weight. Not only does weight control allow women a sense of control in their lives, but also weight serves as a protective factor. Women may lose weight in order to shed their feminine sexuality, reducing their breasts and hips. Feminist theorists hypothesize that the emaciated, boyish body type is a rejection of society's objectification of women's bodies. Alternatively, some women may gain weight to hide curves and femininity to avoid being seen as a sex object, to take up as much physical space as men, and to be taken more seriously. Both extreme weight loss and weight gain may allow women to escape sexual harassment and assault. (Please turn to page 14) Extreme weight gains and losses also are viewed as "posttraumatic responses" to sexual abuse. In addition, women may attempt to erase reminders of sexual abuse by minimizing their sexuality. In support of this posttraumatic response theory, 
research shows small but consistent relationships between the experience of sexual abuse and body image and eating disturbance.

A third feminist theory of body image disturbance relates to Anxieties about Female Appearance and Achievement. Researchers theorize that women today are faced with a difficult task of balancing achievement within professions that historically have been male-dominated while remaining "sufficiently feminine." (Please turn to page 15) If women do not manage this balance, they may face discrimination. In response to the pressure, women may attempt to appear less threatening by losing weight. A woman shaped like a prepubescent girl may appear meek and incapable which, ironically, may allow her to continue working alongside men within her chosen profession. Research generally supports this hypothesis. Thinner women are more likely to be hired and promoted. Additional support for this theory comes from studies that show eating disorder symptoms increase during periods of high achievement stress, such as college graduation. (Please turn to page 16)

In conclusion, body image and eating disturbance are widespread problems facing girls and women. Feminists theorize that disturbance is a result of societal pressures and unattainable goals, not personal deficiencies. Naomi Wolf has stated that chronic dieting leads to passivity, anxiety, emotionality, and low self-esteem. Women need to pull together to challenge the beauty myth, both individually and as a group. Working together to rid ourselves of paralyzing anxieties about our weight and shape could bring about phenomenal achievements. Basing our self-esteem on things other than our outward appearance, like our intellect and creativity, would re-open the door for women 
to thrive personally, professionally, and socially. We have the ability to empower ourselves to make desperately needed and long lasting societal changes.

So how can we empower ourselves, our mothers, sisters, and friends? (Please turn to page 17) First, you can define what being a feminist means to you. Perhaps stop buying fashion magazines that have been shown to decrease self-esteem and body image satisfaction. Why should you pay to feel badly about yourself? Defy stereotypes: wear pink ruffles to your women's studies classes or fix the engine in your car. Compliment women on positive internal characteristics, not their appearance. Do not laugh politely at offensive jokes. Educate yourself and others on the current state of women's health nationally and globally, and determine how you can help. (Please turn to page 18) Volunteer at a shelter, turn off the television, join a campus group, hold workshops, share your knowledge, vote, use your voice and be heard.

Most importantly, nourish yourself and revel in your own beauty. (Please turn to page 19) Embrace your shape and appreciate the amazing things your body can do. Through self-acceptance and rejection of socially prescribed notions of how we should look, we can change the world for ourselves and for our daughters. 
APPENDIX N: FEMINIST THEORY INTERVENTION IMAGE EXAMPLE 


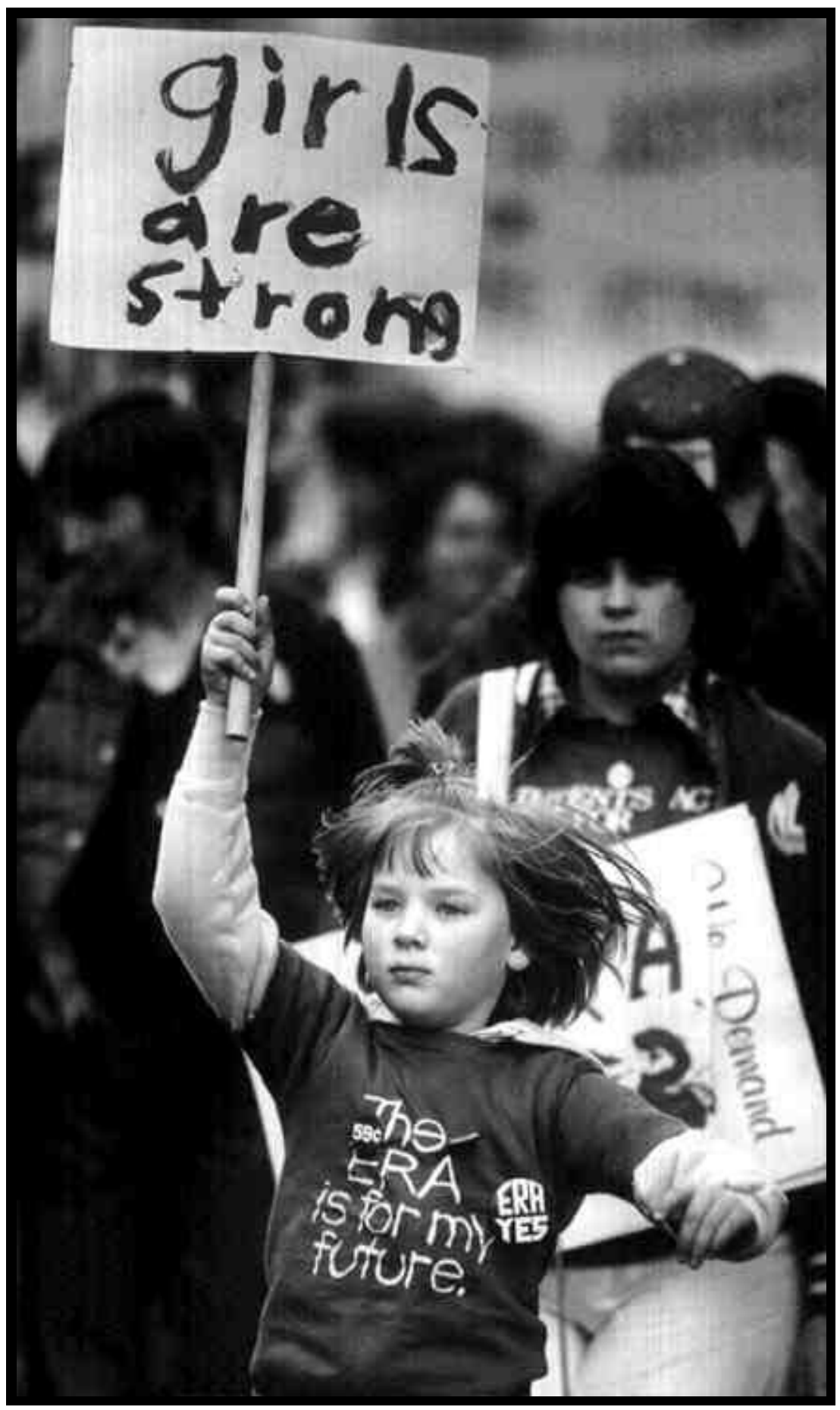




\section{APPENDIX O: PSYCHOEDUCATIONAL INTERVENTION}

\section{TRANSCRIPT}


Throughout history, there have been ideals of beauty, especially for women. Recently, the ideal feminine shape is one that most women cannot attain. The disparity between the ideals represented in the media and the average American woman's appearance often leads to body image dissatisfaction. Women are reminded everyday through television, magazines, billboards, and other forms of media that they don't measure up to the ideal. Sociocultural theory of body image disturbance asserts that society's obsession with thinness and women's continual exposure to images of ultra-thin women leads to undue and unrealistic pressure on women to become the ideal. (Please turn to page 2 ) Women are lead to believe that their bodies are "infinitely malleable." Realistically, bodies are not responsive to continual alterations; most women will never attain the shape publicized by the media. The media make promises that when women finally reach the appearance goals set forth for them, they will truly have happiness, health, and self-esteem. In pursuit of these visions of happiness, women spend billions of dollars struggling to acquire the ideal.

The societal ideal has changed greatly over the course of human existence.

Previously, the standards for beauty were more congruent with reproduction and a natural female shape, such as wide hips. Between the 14th and 17th centuries, a round, curvaceous body was the epitome of sexual desire. (Please turn to page 3 ) Following this trend, during the Victorian age the "corseted figure" was the ideal. Corsets were designed to "cinch" in the waist. This beauty trend led to the use of "fainting" furniture. Couches and chairs actually were placed at the tops and bottoms of stairs because women were unable to breathe well enough while wearing corsets and would often faint after walking up or down stairs! 
During the 1920s in America, the fashion trend described as a "flapper" emerged. This flat-chested, boyish shaped ideal led American women to restrict their eating severely to achieve the "flapper" look. That's when doctors noted the emergence of disordered eating. (Please turn to page 4) Later, in the 1950s, there was a resurgence of the voluptuous woman, exemplified by Marilyn Monroe, but soon after, the 1960s introduced a new icon -- an ultrathin model by the name of Twiggy who was 5 feet 7 inches and weighed a mere 98 pounds.

Since the 1960s, American culture has witnessed an enormous increase in the variety of cosmetic surgery procedures and the number of people electing to have them. In addition, there are many nonsurgical procedures that have become popular, like chemical peels and even Botox injections that decrease wrinkles. Despite the fact that the Botox bacteria in larger amounts can cause Botulism which can result in paralysis and death, "Botox parties" have become commonplace. (Please turn to page 5) Plastic surgery and the growing number of non-surgical appearance-altering techniques all take people further away from their original and biologically driven physical appearance. Extremely thin women now can have large breasts, and 60 year-old women can have virtually wrinkle-free faces. Cultural standards of beauty have begun to outweigh biological influences. Not only are many cosmetic alterations such as nose jobs not biologically beneficial, but many are in direct opposition to health, such as crash dieting, and breast implants.

Studies of body shape trends throughout the last century in America have supported the sociocultural hypothesis. (Please turn to page 6) Over time, average weights for highly visible women, such as Playboy models and Miss America Pageant 
winners, have dropped. Not only have the models become thinner, but also their shape has changed from the natural curvaceous figure of a woman to a more "tubular" shape, with smaller breasts and hips. This is in direct contrast to the average American woman who has become heavier. Weights of idealized women like Miss America and Playboy Models have "stabilized" around 13 to $19 \%$ below recommended weight ranges. This is alarming because one criterion for the diagnosis of anorexia nervosa is a weight $15 \%$ below weight standards. So, a majority of the women in the media may be classified as having one of the major symptoms of an eating disorder. (Please turn to page 7)

The media is said to obscure the line between truth and fiction through many different techniques. For example, in response to viewing photos of herself, supermodel Cindy Crawford was quoted as saying that she wished she looked as good as the woman in the pictures. This exemplifies the fact that models do not even look like the photographs or films of themselves and they certainly are not representative of the average woman. The average model is 5 feet 10 inches tall and 110-pounds, whereas the average American woman is 5 feet 4 inches tall and 145-pounds. What media images do not explain is that the tall, emaciated look of models is a shape naturally attained by only 5 to $10 \%$ of the population. This leaves $90-95 \%$ of women striving to meet a biologically impossible shape. (Please turn to page 8) What's more, those achieving supermodel status still aren't good enough...their appearance is altered in a variety of ways. Most of us don't realize the amount of work that goes into each photograph or commercial. Before being signed to a modeling agency, many models have already had cosmetic surgery, whether it be on her nose, breasts, or lips. Before the "shoot," models spend hours with hair, make-up, and clothing professionals to make them look the best that they 
can. Once the photos are taken, they can be digitally enhanced in case the 5 feet 10 inch, 110-pound woman is still too heavy, or has a bulge or dimple. Legs often are lengthened, leading models to appear even taller and thinner. (Please turn to page 9) If the makeup artist did not cover every tiny skin "imperfection," it can be airbrushed out. Even if selfstarvation, plastic surgery, hours of attention by beauty care professionals, computer enhancement, and airbrushing are not enough to attain the perfect ideal, body parts from other models can be combined to create an illusion of an "ideal" woman. Ironically, these "perfect" female body parts are sometimes the legs, arms, or torso of an adolescent boy! What the average 5 feet 4 inch, 145-pound American woman sees is the picture of a model who may not resemble herself or who may not exist at all. (Please turn to page 10) The irony is that we see models promoting beauty products, weight loss products, and exercise products, promising that if we just try hard enough and spend enough money, we too can attain their looks...the looks that even they don't really have!

Fed up with the unrealistic ideals portrayed in the media, a very courageous actor Jamie Lee Curtis, nicknamed "the bod" and known for her perfect physique, shocked the world when she decided she wanted to do something to help average women rather than contribute to the unrealistic ideas about how women can and should look. In a 2002 photo shoot with More magazine, Jamie Lee decided to show the world what a real 43-year-old woman looks like. (Please turn to page 11) She posed with no make-up or professional hairstyling in a sports bra and bike shorts to reveal what she really looks like. She candidly shared that she is "soft" in the middle and has a bit of a tummy that is usually well-hidden. Then Jamie Lee posed for a traditional magazine photo that was taken after 
three hours of work by 13 different people. The contrast between the photos was striking, making a powerful statement for all women (as well as for men) to hear.

The advertising industry is an incredibly powerful machine. Advertisers spend an estimated \$130 BILLION dollars every year. (Please turn to page 12) Much of this is funneled towards making women feel badly enough about themselves to spend over $\$ 33$ billion dollars on diet products, $\$ 20$ billion dollars on cosmetics, and \$300 million dollars on cosmetic surgery to attain the impossible ideal. It is estimated that each day the average American is exposed to 1500 advertisements. An estimated 1 in every 11 commercials sends direct messages about beauty, and this estimation does not include the indirect messages of every commercial that features beautiful people.

Avoiding the influences of unattainable ideals is virtually impossible. In the average American household, the television is on over seven hours a day and people spend a year and a half of their lives watching commercials. (Please turn to page 13) All of this television reminds viewers, particularly women, of the discrepancy between their actual body shapes and those portrayed as the ideal. For those who avoid television, it is estimated that as many as $83 \%$ of girls and women read fashion magazines. In magazines, women receive 63 messages to be slim and stay in shape for every one such message targeted to men.

Although effective for selling products, we know that exposure to advertisements featuring unrealistic body ideals can increase body dissatisfaction. Women shown pictures of "ultra-thin" models report increases in depression, insecurity, and body dissatisfaction as compared to women exposed to average sized models. (Please turn to page 14) Another striking example of this occurred on the sheltered Island of Figi where 
the traditional female ideal was round and voluptuous. In 1995, islanders were introduced to television and western standards of beauty. Only three years later, researchers documented a dramatic increase in body image and eating disturbance, with girls reporting that they felt "too big or fat" which led them to begin dieting. Most women in America are dissatisfied with their bodies, which is a strong predictor of the development of an eating disorder. As the weights of models have decreased, rates of eating disorders have astronomically increased. (Please turn to page 15)

In addition to impossible weight standards, all non-Caucasian women are faced with an ideal that does not include their skin tone, eye and hair color, or body shape. This lack of representation leads to a larger discrepancy between the way they look and the blond-haired, blue-eyed models in the magazines. Therefore, it is unfortunate but not surprising that body image and eating disturbance are also on the rise among minorities in the U.S.

Sadly, sociocultural pressures are not reserved for adult women. A study found that five-year-old girls' body shape ideals were significantly thinner than their current body shape. The "perfect girl" as reported by Caucasian girls is described as 5 feet 7 inches tall, 100-pounds, a size five, with long blond hair, and big blue eyes. (Please turn to page 16) This "perfect girl" bares a striking resemblance to an American icon named "Barbie." Ninety percent of girls 3 to 11 own one or more Barbie dolls. Little do people know that if Barbie were a real person she would be 7 feet tall, her legs would take up $75 \%$ of her body, her head would be bigger around than her waist, and her chest would be so large that she would not be able to walk upright and she would have to crawl on her hands and knees. 
In conclusion, ideal shapes of women have existed throughout history. Recently, the ideal has changed from a more natural curvaceous shape to a thin and angular shape, much in contradiction to evolution, biology, and how women's natural bodies are supposed to look. (Please turn to page 17) The sociocultural theory asserts that our society is obsessed with the thin ideal that is advocated in some form or another to women everyday through the media. Moreover, this ideal, which only $5 \%$ of the population is able to attain, is made to appear as the norm that is within reach to all women who are disciplined enough. Many of the female icons in the media, like Playboy centerfolds and Miss America winners, are so underweight that they meet at least one criterion for a potentially deadly eating disorder.

It is important for women to realize that the images they see often do not realistically represent the models in the photos. (Please turn to page 18) Digitally altering images of female models is commonplace within the advertising world, and unhealthy weight loss methods like dieting, purging, and over-exercising, are popular among those in the modeling industry. Therefore, the unrealistic ideal is even impossible for the supermodels who set the cultural standards for attractiveness. Women need to be made aware that the ideals they are exposed to are unrealistic and unhealthy to pursue. (Please turn to page 19) The hope is that increased awareness will lead to shifting our focus to self-acceptance and healthy living in place of obsessive dieting and body dissatisfaction. 
APPENDIX P: PSYCHOEDUCATIONAL INTERVENTION IMAGE EXAMPLE 


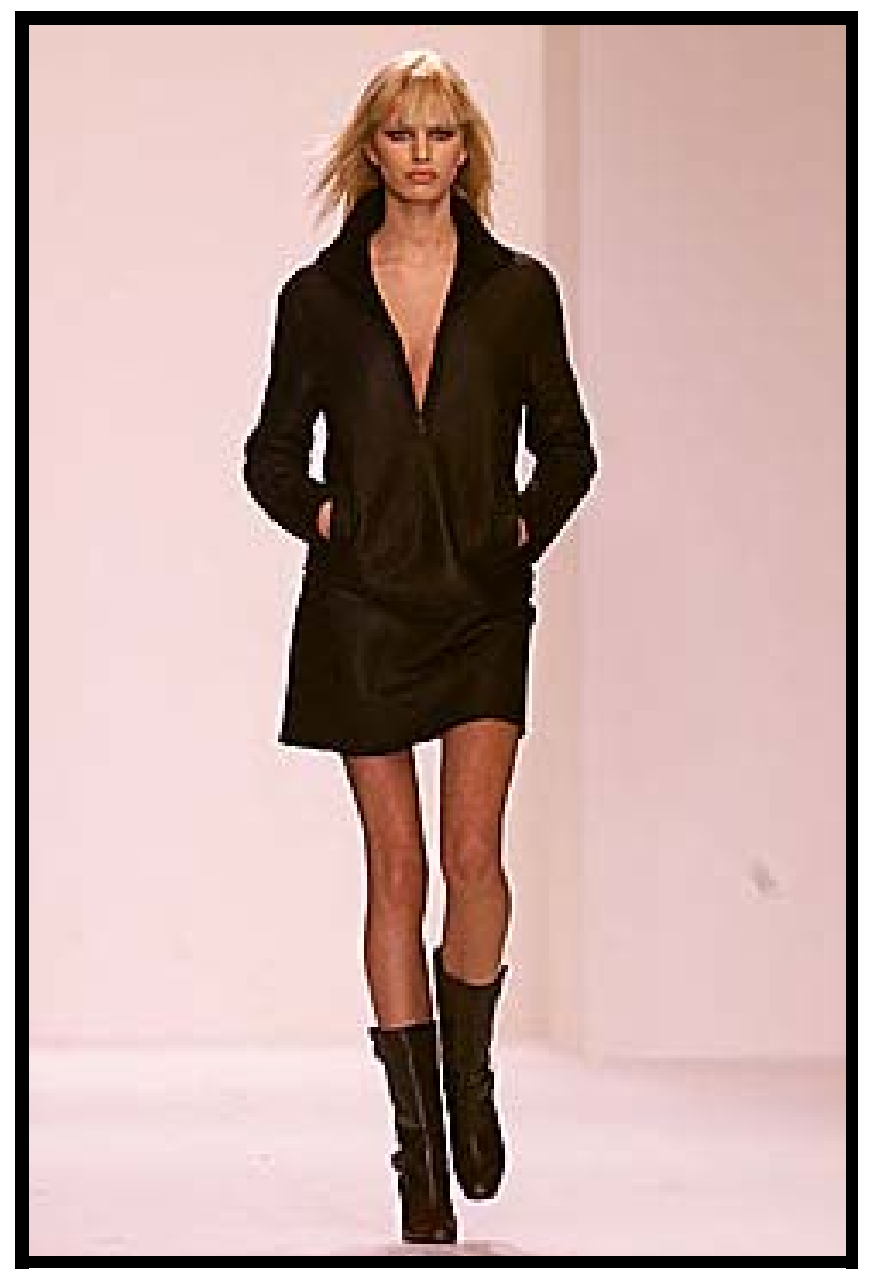


APPENDIX Q: IRB HUMAN SUBJECTS APPROVAL LETTER 
Office of Research

Central

Florida

October 22, 2003

Rachel Peterson

University of Central Florida

Department of Psychology

P.O. Box 161390

Orlando, FL 32816-1390

Dear Ms. Peterson:

With reference to your protocol entitled, "The Effects of Exposure to Feminist Ideology on Women's Body Image," I am enclosing for your records the approved, executed document of the UCFIRB Form you had submitted to our office.

Please be advised that this approval is given for one year. Should there be any addendums or administrative changes to the already approved protocol, they must also be submitted to the Board. Changes should not be initiated until written IRB approval is received. Adverse events should be reported to the IRB as they occur. Further, should there be a need to extend this protocol, a renewal form must be submitted for approval at least one month prior to the anniversary date of the most recent approval and is the responsibility of the investigator (UCF).

Should you have any questions, please do not hesitate to call me at 823-2901.

Please accept our best wishes for the success of your endeavors.

Cordially,

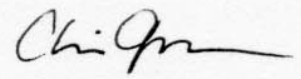

Chris Grayson

Institutional Review Board (IRB)

Copies: Stacey Tantleff-Dunn, Ph.D. IRB File

Office of Research

12443 Research Parkway Suite 207 • Orlando, FL 32826-3252

407-823-3778 • FAX 407-823-3299

An Equal Opportuntity and Affirmative Action Institution 


\section{IRB COMMITTEE APPROVAL FORM FOR UCF/OOR/IRB USE ONLY}

PI(s) Name: Rachel Peterson

Title: The Effects of Exposure to Feminist Ideology on Women's Body Image.

\section{Check as applicable (optional):}

[ ]Yes [ ]No $\begin{aligned} & \text { Have sufficient assurances been given to the committee to establish that } \\ & \text { the potential value of this research exceeds the risks involved? }\end{aligned}$
[ ]Yes [ ]No $\begin{aligned} & \text { Written and oral presentations must be given to participating subjects } \\ & \text { (parents or guardians, if minors) informing them of the protocol, possible } \\ & \text { risks involved, the value of the research, and the right to } \\ & \text { withdraw at any time. }\end{aligned}$
[ ]Yes [ ]No
A signed written consent must be obtained for each human subject
participant.

\section{$\underline{\text { Committee Members: }}$}

Dr. Theodore Angelopoulos:

Ms. Sandra Browdy:

Dr. Jacqui Byers:

Dr. Ratna Chakrabarti:

Dr. Karen Dennis:

Dr. Barbara Fritzsche:

Dr. Robert Kennedy:

Dr. Gene Lee:

Ms. Gail McKinney:

Dr. Debra Reinhart:

Dr. Valerie Sims:

W] Expedited

Dated: $210 \mathrm{CT} 2003$

[ ] Exempt

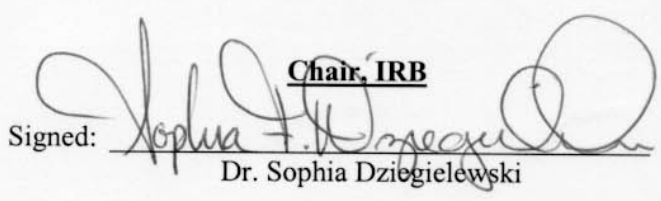

Dated: 


\section{LIST OF REFERENCES}

American Psychiatric Association (2000). Diagnostic and statistical manual of mental disorders (text revision). Washington, DC.

Baranowski, M. J. \& Hetherington, H. M. (2001). Testing the efficacy of an eating disorder prevention program. International Journal of Eating Disorders, 29, 119124.

Bargad, A. \& Hyde, J. (1991). Women's studies: A study of feminist identity development in women. Psychology of Women Quarterly, 15, 181-201.

Beck, J. (1995). Cognitive therapy: Basics and beyond. Philadelphia, PA: Beck Institute for Cognitive Therapy \& Research.

Bem, S. L. (1974). The measurement of psychological androgyny. Journal of Consulting \& Clinical Psychology, 42(2), 155-162.

Brown, T. A., Cash, T. F., \& Mikulka, P. J. (1990). Attitudinal body-image assessments: Factor analysis of the body-self relations questionnaire. Journal of Personality Assessment, 55, 135-144.

Burger, J. M. (1987). Desire for control and conformity to a perceived norm. Journal of Personality and Social Psychology, 53(2), 355-360.

Campbell, R., \& Wasco, S. (2000). Feminist approaches to social science: Epistemological and methodological tenets. American Journal of Community Psychology, 28 (6), 773-790.

Cash, T. F., Ancis, J., \& Strachan, M. (1997). Gender attitudes, feminist identity, and body images among college women. Sex Roles, 36 (7/8), 433-447. 
Cash, T. F. \& Henry, P. E. (1995). Women's body images: The results of a national survey in the U.S.A. Sex Roles, 33, 19-27.

Cash, T.F., \& Labarge, A.S. (1996). Development of the appearance schemas inventory: A new cognitive body-image assessment. Cognitive Therapy and Research, 20, 37-50.

Cohen, J. (2003). A power primer. In A. E. Kazdin (Ed.), Methodological Issues and Strategies in Clinical Research-Third Edition (pp. 427-436). Washington, DC: American Psychological Association.

Dahlgren Daigneault, S. (2000). Body Talk: A school-based group intervention for working with disordered eating behaviors. Journal Specialists in Group Work, 25 (2), 191-213.

Davis, C., Dionne, M., \& Lazarus, L. (1996). Gender-role orientation and body image in women and men: The moderating influence of neuroticism. Sex Roles, 34 (7/8), 493-505.

Dionne, M., Davis, C., Fox, J. \& Gurevich, M. (1995). Feminist ideology as a predictor of body dissatisfaction in women. Sex Roles, 33(3/4), 277-287.

Fairburn, C., Jones, R., Peveler, R. C., Hope, R.A., \& O'Connor, M. (1993). Psychotherapy and bulimia nervosa. Archives of General Psychiatry, 50, 419428. 
Fairburn, C., Norman, P.A., Welch, S.L., O’Connor, E.M., Doll, A.H., \& Peveler, R.C. (1995).A prospective study of outcome in bulimia nervosa and the long-term effects of three psychological treatments. Archives of General Psychiatry, 52, 304-312.

Fallon, P., Katzman, M., \& Wooley, S. (1994). Feminist perspectives on eating disorders. New York: The Guilford Press.

Fischer, A., Good, G., \& Hill, M. (2000). Assessing women's feminist identity development. Psychology of Women Quarterly, 24, 15-29.

Garner, D.M. (1991). The eating disorder inventory-2 professional manual. Odessa, FL: Psychological Assessment Resources.

Garner, D. M. \& Garfinkel, P. E. (1979). The eating attitudes test: An index of the symptoms of anorexia nervosa. Psychological Medicine, 9 (2), 273-279.

Garner, D.M., Olmstead, M.P., \& Polivy, J. (1983). Development and validation of a multidimensional eating disorder inventory for anorexia and bulimia. International Journal of Eating Disorders, 2, 15-34.

Gilbert, S. \& Thompson, J. (1996). Feminist explanations of the development of eating disorders: Common themes, research findings, and methodological issues. Clinical Psychology: Science \& Practice, 3, 183-202.

Glidden, C., \& Tracey, T. (1989). Women's perceptions of personal sociocultural counseling interventions. Journal of Counseling Psychology, 36 (1), 54-62.

Hawkins, R., Turell, S., \& Jackson, L. (1983). Desirable and undesirable masculine and feminine traits in relation to students' dieting tendencies and body image dissatisfaction. Sex Roles, 9, 705-718. 
Heinberg, L. J. \& Thompson, J. K. (1995). Body image and televised images of thinness attractiveness: A controlled laboratory investigation. Journal of Social and Clinical Psychology, 14 (4), 325-338.

Heinberg, L., Thompson, J. K., \& Stormer, S. (1995). Development and validation of the sociocultural attitudes towards appearance questionnaire. International Journal of Eating Disorders, 17 (1), 81-89.

Irving, L. (1990). Mirror images: Effects of the standard of beauty on the self and bodyesteem of women exhibiting varying levels of bulimic symptoms. Journal of Social and Clinical Psychology, 9 (2), 230-242.

Irving, L. \& Berel, S. (2001). Comparison of media-literacy programs to strengthen college women's resistance to media images. Psychology of Women Quarterly, $25,103-111$.

Jackson, L., Sullivan, L., \& Rostker, R. (1988). Gender, gender role, and body image. Sex Roles, 19 (7/8), 429-433.

Johnson, C. \& Petrie, T. (1995). The relationship of gender discrepancy to eating disorder attitudes and behaviors. Sex Roles, 33 (5/6), 405-416.

Katzman, M. A. \& Wolchik, S. A. (1984). Bulimia and binge eating in college women: A comparison of personality and behavioral characteristics. Journal of Consulting and Clinical Psychology, 52 (3), 423-428.

Kendler, K., MacLean, C., Neale, M., Kessler, R., Heath, A., Phil, D., \& Lindon, E. (1991). The genetic epidemiology of bulimia nervosa. The American Journal of Psychiatry, 148 (12), 1627-1637. 
Keppel, G. \& Zedeck, S. (1998). Data Analysis for Research Designs: Analysis of Variance and Multiple Regression/Correlation Approaches. New York: W. H. Freeman and Company.

Kilbourn, J. (Writer/Presenter), \& Jhally, S. (Producer/Director) (1995). Slim hopes: advertising and the obsession with thinness [Motion Picture]. United States: Media Education Foundation.

Killen, J. D., Barr Taylor, C. B., Hammer, L. D., Litt, I., Wilson, D. M., Rich, T., Hayward, C., Simmonds, B., Kraemer, H., \& Varady, A. (1993). An attempt to modify unhealthful eating attitudes and weight regulation practices of young adolescent girls. International Journal of Eating Disorders, 13, 369-384.

Kimlicka, T., Cross, H., \& Tarnai, J. (1983). A comparison of androgynous, feminine, masculine, and undifferentiated women on self-esteem, body satisfaction, and sexual satisfaction. Psychology of Women Quarterly, 7 (3), 291-295.

Kitzinger, C. (2000). Doing feminist conversion analysis. Feminism and Psychology, 10(2), 163-193.

Kleinplatz, P., McCarrey, M., \& Kateb, C. (1992). The impact of gender-role identity on women's self-esteem, lifestyle satisfaction, and conflict. Canadian Journal of Behavioural Science, 24(3), 333-347.

Kline, R. B. (2004). Beyond Significance Testing: Reforming Data Analysis Methods in Behavioral Research. Washington DC: American Psychological Association.

Lavin, M. A., \& Cash, T. F. (2001). Effects of exposure to information about appearance stereotyping and discrimination on women's body images. International Journal of Eating Disorders, 29, 51-58. 
Leon, G., Fulkerson, J., Perry, C., \& Cudeck, R. (1993). Personality and behavioral vulnerabilities associated with risk status for eating disorders in adolescent girls. Journal of Abnormal Psychology, 102 (3), 438-444.

Lull, J., Mulac, A., \& Rosen, S. (1983). Feminism as a predictor of mass media use. Sex Roles, 9(2), 165-177.

Mason, N. S., \& Chaney, J. (1996). Bulimia nervosa in undergraduate women: Factors associated with internalization of the sociocultural standard of thinness. Applied \& Preventative Psychology, 5, 249-259.

Mintz, L. \& Betz, N. (1986). Sex differences in the nature, realism, and correlates of body image. Sex Roles, 15 (3/4), 185-195.

Moskowitz, J. M. (1989). The primary prevention of alcohol problems: A critical review of the research literature. Journal of Studies on Alcohol, 50(1), 54-88.

Murnen, S., \& Smolak, L. (1997). Femininity, masculinity, and disordered eating: A meta-analytic review. International Journal of Eating Disorders, 22(3), 231-242.

Perlick, D. \& Silverstein, B. (1994). Faces of female discontent: Depression, disordered eating, and changing gender roles. In P. Fallon, \& M. A. Katzman (Eds.), Feminist perspectives on eating disorders (pp. 77-93). New York, NY: The Guilford Press.

Piran, N. (1995). Prevention: Can early lessons lead to a delineation of an alternative model? A critical look at prevention with schoolchildren. Eating Disorders, 3 (1), 28-37.

Rappaport, J. (1987). Terms of empowerment/exemplars of preventions toward a theory for community psychology, 15 (2), 121-142. 
Reed, D. L., Thompson, J.K., Brannick, M.T., \& Sacco, W.P. (1991). Development and validation of the physical appearance state and trait anxiety scale. Journal of Anxiety Disorders, 5, 323-332.

Rickard, K. M. (1987, March). Feminist identity development: Scale development and initial validation studies. Paper presented at the meeting of the Association for Women in Psychology, Denver, CO.

Rodin, J., Silberstein, L.R., \& Striegel-Moore, R.H. (1984). Women and weight: A normative discontent. In T.B. Sonderegger (Ed.), Nebraska symposium on motivation: Psychology and gender (pp.267-307). Lincoln: University of Nebraska Press.

Rogers E., Chamberlin J., Ellison M., \& Crean T. (1997). A consumer-constructed scale to measure empowerment among users of mental health services. Psychiatric Services, 48 (8), 1042-1047.

Rosenberg, M. (1965). Society and the adolescent self-image. Princeton, New Jersey: Princeton University Press.

Rosnow, R. L., \& Rosenthal, R. (2003). Effect sizes for experimenting psychologists. Canadian Journal of Experimental Psychology, 57 (3), 1196-1961.

Smolak, L., \& Murnen, S.K. (2002). A meta-analytic examination of the relationship between child sexual abuse and eating disorders. International Journal of Eating Disorders, 31, 136-150.

Snyder, R. \& Hasbrouck, L. (1996). Feminist identity, gender traits, and symptoms of disturbed eating among college women. Psychology of Women Quarterly, 20, 593-598. 
Springer, E. A., Winzelberg, A. J., Perkins, R., \& Barr Taylor, C. (1999). Effects of body image curriculum for college students on improved body image. International Journal of Eating Disorders, 26, 13-20.

Streigel-Moore, R. (1995). A feminist agenda for psychological research on eating disorders. In P. Fallon, \& M. A. Katzman (Eds.), Feminist perspectives on eating disorders (pp. 438-454). New York, NY: The Guilford Press.

Streigel-Moore, R., Silberstein, L., \& Rodin, J. (1986). Toward an understanding of risk factors for bulimia. American Psychologist, 41 (3), 246-263.

Stice, E. (1994). Review of the evidence for a sociocultural model of bulimia nervosa and an exploration of the mechanisms of action. Clinical Psychology Review, 14 (7), 633-661.

Stice, E., Chase, A., Stormer, S., \& Appel, A. (2001). A randomized trial of dissonancebased eating disorder prevention programs. International Journal of Eating Disorders, 29, 247-262.

Stice, E., Mazotti, L., Weibel, D., \& Agras, W. S. (2000). Dissonance prevention program decreases thin-ideal internalization, body dissatisfaction, dieting, negative affect, and bulimic symptoms: A preliminary experiment. International Journal of Eating Disorders, 27, 206-217.

Stice, E. \& Ragan, J. (2002). A preliminary controlled evaluation of an eating disturbance psychoeducational intervention for college students. International Journal of Eating Disorders, 31, 59-171.

Stice, E. \& Shaw, H. (2004). Eating disorder prevention programs: A meta-analytic review. Psychological Bulletin, 130 (2), 206-227. 
Stice, E., Trost, A., \& Chase, A. (2003). Healthy weight control and dissonance-based eating disorder prevention programs: Results from a controlled trial. International Journal of Eating Disorders, 33, 10-21.

Stormer, S. (1999). The cross-gender effects of an experimental media focused psychoeducation program. Unpublished doctoral dissertation, University of South Florida, Tampa.

Thompson, J.K., Heinberg, L.J., Altabe, M., \& Tantleff-Dunn, S. (1999). Exacting beauty: Theory, assessment, and treatment of body image disturbance. New York: American Psychology Association Books.

Thompson, J.K. \& Thompson, C.M. (1986). Body size distortion and self-esteem in asymptomatic, normal weight males and females. International Journal of Eating Disorders, 5(6), 1061-1068.

Thompson, M. A. \& Gray, J. J. (1995). Development and validation of a new body image assessment scale. Journal of Personality Assessment, 64 (2), 258-269.

Tilgner, L., Wertheim, E. H., \& Paxton, S. J. (2004). Effects of social desirability on adolescent girls' responses to an eating disorders prevention program. International Journal of Eating Disorders, 35, 211-216.

Timko, C., Streigel-Moore, R., Silberstein, L., \& Rodin, J. (1987). Femininity/Masculinity and disordered eating in women: How are they related? International Journal of Eating Disorders, 6 (6), 701-712.

Whiteley, B.F. (1983). Sex role orientation and self-esteem: A critical meta-analytic review. Journal of Personality \& Social Psychology, 44(4), 765-778. 
Williamson, D. A., Kelley, M. L., Davis, C. J., Ruggiero, L., \& Blouin, D. C. (1985). Psychopathology of eating disorders: A controlled comparison of bulimic, obese, and normal subjects. Journal of Consulting and Clinical Psychology, 53, 161-166.

Wiseman, C., Gray, J., Mosimann, J., \& Ahrens, A. (1992). Cultural expectations of thinness in women: An update. International Journal of Eating Disorders, 11 (1), 85-89.

Withers, G. F. \& Wertheim, E. H. (2004). Applying the Elaboration Likelihood Model of persuasion to a videotape-based eating disorders primary prevention program for adolescent girls, Eating Disorders, 12, 103-124.

Xinaris, S., \& Boland, F.J. (1990). Disordered eating in relation to tobacco use, alcohol consumption, self-control, and sex-role ideology. International Journal of Eating Disorders, 9, 425-433.

Zabinski, M. F., Wilfley, D. E., Pung, M. A., Winzelberg, A. J., Eldredge, K., \& Taylor, C. B. (2001). An interactive internet-based intervention for women at risk of eating disorders: A pilot study. International Journal of Eating Disorders, 30, 129-137. 